\title{
Protective effect of the extremolytes ectoine and hydroxyectoine in a porcine organ culture
}

\author{
Teresa Tsai $^{1}$ • Ana M. Mueller-Buehl ${ }^{1}$ - Yathavan Satgunarajah ${ }^{1} \cdot$ Sandra Kuehn ${ }^{1} \cdot$ H. Burkhard Dick ${ }^{1}$. \\ Stephanie C. Joachim ${ }^{1}$ (1)
}

Received: 11 December 2019 / Revised: 17 June 2020 / Accepted: 15 July 2020

(C) The Author(s) 2020, corrected publication 2021

\begin{abstract}
Purpose Hypoxic damage to the retina is a relevant component of neurodegenerative pathologies such as glaucoma or retinal ischemia. In porcine retina organ cultures, hypoxic damage can be induced by applying cobalt chloride $\left(\mathrm{CoCl}_{2}\right)$. The aim of our study was to investigate possible neuroprotective effects of the extremolytes ectoine and hydroxyectoine in this hypoxiadamaged retina model.

Methods To simulate hypoxia, porcine retina organ cultures were damaged with $300 \mu \mathrm{M} \mathrm{CoCl}_{2}$ for $48 \mathrm{~h}$ starting on day $1\left(n=8_{-}\right.$ 9/group). In order to investigate the possible neuroprotective effects of ectoine and hydroxyectoine, $0.5 \mathrm{mM}$ of each extremolyte was added to the culture at the same time as the stressor and for the same duration. On day 8, the retina organ cultures were taken for (immuno)-histochemical examinations. Retinal ganglion cells (RGCs), macroglia, and apoptotic and hypoxic cells were detected with appropriate markers followed by cell counts and group comparisons.

Results Treatment with ectoine resulted in RGC protection $(p<0.05)$ and reduced rate of apoptosis $(p<0.001)$ in hypoxiatreated retina organ cultures. However, the macroglia area and the amount of hypoxic, HIF-1 $\alpha^{+}$cells were unaffected by the ectoine treatment $(p=0.99)$. Treatment with hydroxyectoine also protected RGCs $(p<0.01)$ by inhibiting apoptosis $(p<0.001)$. In addition, the number of hypoxic, HIF- $1 \alpha^{+}$cells could be significantly reduced by treatment with hydroxyectoine $(p<0.05)$. The macroglia area on the other hand was unchanged after $\mathrm{CoCl}_{2}$ and treatment with hydroxyectoine.

Conclusion Both extremolytes had a protective effect on $\mathrm{CoCl}_{2}$-induced hypoxia in the porcine retina organ culture. Regarding the reduction of hypoxic stress, hydroxyectoine appears to be more effective. Thus, both extremolytes represent an interesting potential new therapeutic approach for patients with ocular diseases in which hypoxic processes play a significant role.
\end{abstract}

Keywords Extremolytes $\cdot$ Ectoine $\cdot$ Hydroxyectoine $\cdot$ Hypoxia $\cdot$ Porcine organ culture

\section{Introduction}

Hypoxia refers to a mismatch between oxygen demand and oxygen supply, so that a condition exists in which the tissue is not sufficiently supplied with oxygen. Both the structural and functional integrity of the retina depend on its oxygenation. As one of the most metabolically active tissues, oxygen is

Teresa Tsai and Ana M. Mueller-Buehl contributed equally to the work presented here and should therefore be regarded as equivalent authors.

Stephanie C. Joachim stephanie.joachim@rub.de

1 Experimental Eye Research Institute, University Eye Hospital, Ruhr-University Bochum, In der Schornau 23-25, 44892 Bochum, Germany more rapidly consumed by the retina than by other tissues [1]. This makes the retina highly susceptible to hypoxic stress [2]. In many eye diseases, such as ischemic central retinal vein thrombosis and central retinal artery occlusion, hypoxia appears [3]. Furthermore, hypoxia is also involved in the development of diabetic retinopathy $[4,5]$ as well as glaucoma [6-8]. Glaucoma is the second leading cause of blindness worldwide [9]. The estimated number of people affected in 2010 was approximately 60.5 million [10]. By 2040, this number is expected to increase to around 111.8 million [11]. At the forefront of the disease is a progressive optic neuropathy with changes at the optic nerve head, gradual retinal ganglion cell (RGC) death, and visual field loss [9]. The cause of this degeneration is still unclear. An elevated intraocular pressure is still considered as the main risk factor [9], but there are increasing evidences that other pathological factors are 
involved. Another factor possibly involved in glaucoma pathomechanism is hypoxia $[12,13]$. The upregulation of the transcription factor hypoxia-inducible factor-1 (HIF-1), in particular the stabilization of its oxygen-sensitive subunit HIF- $1 \alpha$, is a hallmark of hypoxic processes [14]. In most cell types without hypoxia, HIF-1 $\alpha$ is undetectable due to the immediate degradation by the ubiquitin-proteasome pathway [15]. In contrast, hypoxic processes lead to an increase amount of HIF- $1 \alpha$, which enters the nucleus and in turn induces the expression of various hypoxic genes [16, 17]. Interestingly, in retinas of a high-pressure experimental rat glaucoma model, an upregulation of HIF- $1 \alpha$ and some HIF- $1 \alpha$ target genes was detectable [18]. Moreover, in glaucoma donor eyes, an increased expression of HIF- $1 \alpha$ could be identified in RGCs and the optic nerve axons [19]. All these data indicate that HIF- $1 \alpha$ expression might be a very crucial stage in glaucoma development and therefore a successful target for the implementation of neuroprotective drugs.

Cobalt belongs to the trace elements and is indispensable for the human organism but needed in low concentration. As part of vitamin $B_{12}$, cobalt influences mitotic processes and is essential for neuronal integrity [20]. However, in high concentrations, cobalt has cyto- and neurotoxic effects [21]. Cobalt stabilizes HIF- $1 \alpha$ by binding the oxygen-dependent region and prevents its degradation. Thus, it induces increased gene transcription that would otherwise occur only under hypoxic conditions [21]. Due to its properties as a hypoxia imitator, cobalt chloride $\left(\mathrm{CoCl}_{2}\right)$ is commonly used to induce neurodegeneration in various models including retinal ganglion cell lines or neuroretina explants [22-26]. Previously, we developed an effective and reproducible hypoxia damage model by applying $\mathrm{CoCl}_{2}$ to porcine retina organ cultures. It is characterized by a strong degeneration, which is evidenced by a loss of neuronal cells of the inner retinal layers especially of RGCs. Furthermore, a reduced number of microglia cells, an increase of oxidative stress markers, and increased apoptosis mechanisms could be identified in this model [26].

Extremolytes are small, low-molecular, osmotically active substances that are used by so-called extremophilic organisms. Extremophiles include bacteria that are exposed to extreme temperature, pressure, radiation, $\mathrm{pH}$, or salinity conditions [27]. The extremolytes protect the extremophiles against elevated salt concentrations and allow survival at high water temperatures as well as extreme drought [28]. In addition, they have been shown to stabilize protein structure and prevent denaturation of protein and nucleic acid $[29,30]$. The extremolyte ectoine was first discovered in the halophilic sulfur bacterium Ectothiorhodospira halochrloris, which was isolated from the soda lake in Wadi an-Natrun in Egypt [31]. Hydroxyectoine was detected several years later in the Grampositive bacterium Streptomyces parvulus and differs only in one functional group, the hydroxyl group on the $\mathrm{C} 5$ atom [32]. In contrast to drugs, the extremolytes do not have any pharmacological, metabolic, or immunologic mode of action. They achieve their effects in a purely physical manner by enhancing the H-bonds in water which results in a stabilization of cell membrane surfaces [33]. Based on the described inflammation-reducing and membrane-stabilizing properties of the compatible solutes, many potential applications are described. Currently, dermatology is the main application area as there are indications of positive effects on UVA-induced skin aging. Reduced release of inflammatory factors, protection of Langerhans cells, and a decrease in the number of apoptotic keratinocytes by ectoine after UV treatment could be demonstrated $[34,35]$. Moreover, there is also a positive benefit of ectoine application in the context of inflammatory skin diseases, such as neurodermatitis [36]. Further indications of ectoine containing medical devices with clinically proven efficacy are inhalation solutions, nasal sprays, or eye drops against allergic diseases such as allergic rhinitis [37-39], allergic conjunctivitis [37], dry mucous membranes in the mouth and throat area [40], and respiratory diseases, like bronchial asthma, chronic obstructive pulmonary disease [41-43], and acute rhinosinusitis [44].

The goal of our study was to investigate for the first time possible neuroprotective effects of the extremolytes ectoine and hydroxyectoine in a retinal degeneration organ culture model. Hence, both extremolytes were applied to porcine retinal explants damaged by hypoxia. Cellular stress markers, apoptotic conditions, and RGCs were analyzed. In addition, macroglia cells were assessed. We found that both, ectoine and hydroxyectoine, had a protective effect on $\mathrm{CoCl}_{2}$-induced hypoxia in the porcine retina organ culture. Regarding the reduction of hypoxic stress, hydroxyectoine appears to be more effective.

\section{Material and methods}

\section{Preparation of retinal explants}

The eyes of domestic pigs were obtained from the local abattoir (Bochum, Germany) and retinas were prepared within $3 \mathrm{~h}$ from enucleation. The preparation of retinal explants was performed as described previously $[26,45,46]$. Briefly, the eyeball was opened with scissors to separate the anterior parts of the eye from the eyecup. Subsequently, the eyecup was cut four times to obtain a cloverleaf-like shape. One retinal explant per leaf was punched out in the middle part of the quadrant using a dermal punch $(\varnothing=6 \mathrm{~mm}$, Pfm medical AG, Cologne, Germany). Next, the explants were transferred to a Millicell culture insert (Millipore, Billerica, MA, USA) and cultured, with the photoreceptor layer facing the inserts, in Neurobasal-A medium supplemented with $0.8 \mathrm{mM}$ L-glutamine, $2 \%$ B27®, $1 \%$ N-2 (all from Thermo Fisher Scientific, Schwerte, Germany), and $2 \%$ v/v penicillin/ 
streptomycin (Sigma-Aldrich, St Louis, MO, USA) for 8 days in an incubator $\left(37^{\circ} \mathrm{C}, 5 \% \mathrm{CO}_{2}\right)$. The medium was exchanged completely at day $0,1,2$, and 3 . Additionally, half of the medium volume was replaced after 5 and 7 days. Starting from day 1, retina explants were incubated for $48 \mathrm{~h}$ with $300 \mu \mathrm{M} \mathrm{CoCl}_{2}$ (Sigma-Aldrich, St Louis, MO, USA) to induce a hypoxic environment $[26,47]$. The treatment with the extremolytes was performed simultaneously to the $\mathrm{CoCl}_{2}$ stimulation and took $48 \mathrm{~h}$ in total (Fig. 1). In the first study, we applied ectoine $(0.5 \mathrm{mM}$, Bitop AG, Witten, Germany; Fig. 1a). In a second experiment, hydroxyectoine $(0.5 \mathrm{mM}$, Bitop AG, Witten, Germany; Fig. 1b) was used. The dose of $0.5 \mathrm{mM}$ is based on preliminary data in which two different doses $(0.5 \mathrm{mM}$ and $10 \mathrm{mM})$ of ectoine and hydroxyectoine were tested for their uptake and their effects. On the one hand, it was shown that both ectoine doses were absorbed by the tissue. It was also observed that the higher dose of ectoine reduced the number of RGCs and increased apoptosis. The effect of hydroxyectoine was not quite as pronounced as that effect of ectoine but showed the same tendencies. Control groups for both studies were cultivated without the stressor $\mathrm{CoCl}_{2}$ and with or without additional ectoine/hydroxyectoine treatment. Four groups were compared in each study: control, $\mathrm{CoCl}_{2}$, control + ectoine/hydroxyectoine, and $\mathrm{CoCl}_{2}+$ ectoine/hydroxyectoine. At day 8 , retinal explants were obtained for histological ( $n=8-9 /$ group) and immunohistochemical analyses ( $n=8-9$ /group; Fig. 1$)$.

\section{Histology}

For histological evaluations, the retinal explants were treated for 15 min with $1.5 \%$ paraformaldehyde (Merck Millipore Ltd). Afterwards, incubation with $15 \%$ sucrose solution (VWR International GmbH, Ulm, Germany) for $15 \mathrm{~min}$ and $30 \%$ sucrose solution for $30 \mathrm{~min}$ was performed. Then, the explants were embedded in NEG-50 Tissue Tek medium (Fisher Scientific $\mathrm{GmbH})$ and cryo-cross sections $(10 \mathrm{~mm}$ thick) of the retina explants were cut on a microtome (Thermo Fisher, Waltham, MA, USA). The cryo-crosssections were mounted on Histobond slides (Marienfeld, Lauda-Königshofen, Germany) and fixed in ice-cold acetone for $10 \mathrm{~min}$.

The retinas were stained with hematoxylin and eosin (H\&E) to visualize the different layers of the retina [48]. Two images in the central region of each retinal crosssection were taken in $\times 200$ magnification ( 3 sections per sample, $n=6$ /group) using an Axio Imager.M1 microscope (Zeiss, Jena, Germany). Then, layers and the total retina were analyzed using the built-in measuring tool from Zen 2012 software (Zeiss). The thickness of the whole retina (excluding the outer segments), the ganglion cell layer (GCL), the inner plexiform layer (IPL), the inner nuclear layer (INL), outer plexiform layer (OPL), the outer nuclear layer $(\mathrm{ONL})$, and the whole retina (excluding the outer segments) was measured in three regions per picture and these measurements were averaged.
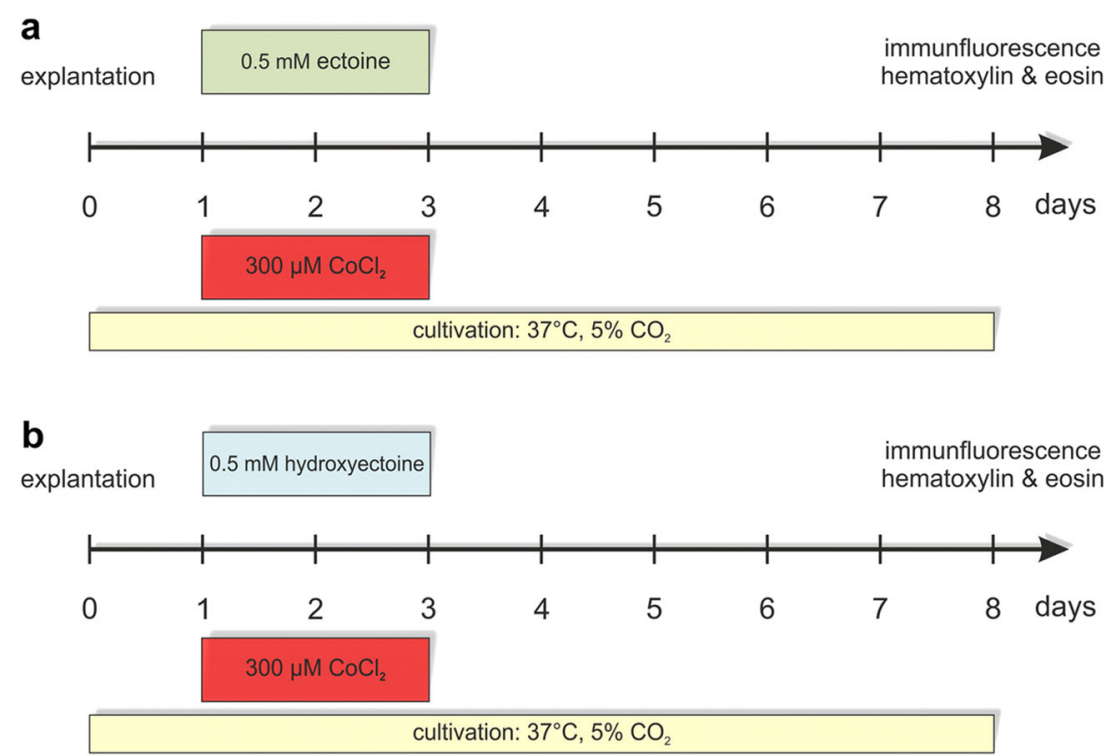

Fig. 1 Experimental design. Cultivation of porcine retinas started with the explantation at day 0 . At day 1 , hypoxia was induced by adding the stressor $\mathrm{CoCl}_{2}(300 \mu \mathrm{M})$ to the medium of cultivated retinas in both studies. $\mathrm{CoCl}_{2}$ remained there for $48 \mathrm{~h}$ until day 3. At day 8 , retinas were prepared for histological and immunohistochemical analyses. (a) To investigate possible neuroprotective effects of ectoine, $0.5 \mathrm{mM}$ ectoine was added to retinas simultaneously to the stressor and remained for 48 h. Four groups were compared: control, ectoine, $\mathrm{CoCl}_{2}$, and ectoine $+\mathrm{CoCl}_{2}$. (b) Hydroxyectoine treatment was also added from day 1 to day 3 of cultivation, simultaneously to $\mathrm{CoCl}_{2}$. In this study, four groups were compared: control, hydroxyectoine, $\mathrm{CoCl}_{2}$, and $\mathrm{CoCl}_{2}+$ hydroxyectoine 
Table 1 Antibodies used for immunohistology analyses

\begin{tabular}{|c|c|c|c|c|c|}
\hline \multicolumn{3}{|l|}{ Primary antibody } & \multicolumn{3}{|l|}{ Secondary antibody } \\
\hline Antibody & Company & Dilution & Antibody & Company & Dilution \\
\hline Anti-Brn-3a & Santa Cruz & $1: 100$ & Donkey anti-goat Alexa Fluor 488 & Dianova & $1: 500$ \\
\hline Anti-cleaved caspase 3 & Sigma-Aldrich & $1: 300$ & Donkey anti-rabbit Alexa Fluor 555 & Jackson Immuno-Research & $1: 500$ \\
\hline Anti-GFAP & Millipore & $1: 3000$ & Donkey anti-chicken $\mathrm{Cy} 3$ & Millipore & $1: 500$ \\
\hline Anti-HIF-1 $\alpha$ & BD Bioscience & $1: 100$ & Donkey anti-mouse Alexa Fluor 555 & Abcam & $1: 500$ \\
\hline Anti-NeuN & Millipore & $1: 400$ & Donkey anti-chicken Alexa Fluor 488 & Jackson Immuno-Research & $1: 500$ \\
\hline Anti-Vimentin & Sigma-Aldrich & $1: 500$ & Goat anti-mouse Alexa Fluor 488 & Invitrogen & $1: 500$ \\
\hline
\end{tabular}

\section{Immunohistology}

For immunohistochemical analyses, retinal cross-sections ( $n=8-9$ /group) were prepared as described under histology. Specific primary antibodies and matched secondary antibodies were used to identify different cell types and proteins of the retina (Table 1).

First, the sections were rinsed in PBS (Santa Cruz Biotechnology, Inc., Dallas, TX, USA) before staining. For the Brn-3a and cleaved caspase-3 staining, the antigens were unmasked by boiling in citrate buffer (0.01 M, pH=6; Bernd Kraft GmbH, Duisburg, Germany) for $10 \mathrm{~min}$. Then, the sections were permeabilized and blocked with a mixture of serum samples (10-20\% donkey or goat serum), $0.1-0.2 \% \mathrm{v} / \mathrm{v}$ Triton X-100 (Sigma-Aldrich Chemie GmbH), and PBS. Dilution of the primary antibodies (Table 1) was performed in the blocking solution and incubated at room temperature overnight. On the next day, the sections were incubated with Cy3/Alexa Fluor 555- or FITClabeled secondary antibodies (Table 1) in the same mixture for $60 \mathrm{~min}$. For all stainings, 4',6 diamidino-2phenylindole (DAPI; SERVA Electrophoresis GmbH, Heidelberg, Germany) was used to visualize the cell nuclei. Finally, the sections were mounted in Shandon $^{\mathrm{TM}}$ EZ-Mount ${ }^{\mathrm{TM}}$ (Fisher Scientific GmbH). For each immunohistochemical staining, negative controls were performed with the secondary antibody only.

\section{Immunohistochemical examination}

For all immunohistochemical stainings, six sections of each retina were stained. Four images (two central and two peripheral) were taken for each section with a fluorescence microscope (Axio Imager M1). In total, immunohistochemical analyses included 24 images per sample. Afterwards, these pictures were masked and cut with a predefined window (Corel PaintShop Pro X8, Corel, Ottawa, Ontario, Canada). For each retinal image, the number of cells labeled with Brn-3a, Brn-3a and cleaved caspase 3 colocalized cells, HIF- $1 \alpha$ labeled cells in the whole retina as well as HIF- $1 \alpha$ cells localized in the GCL, and NeuN and HIF $1 \alpha$ colocalized cells in the GCL, were counted using ImageJ software (version 1.43u, NIH, Bethesda, MD, USA). Cell numbers of control retinas were set as $100 \%$ for all results regarding cell counting.

For GFAP and vimentin, the signal area was measured using an established protocol and an ImageJ software macro $[49,50]$. Briefly, the masked pictures were converted to gray pictures and the background was subtracted (GFAP $=$ ectoine study: 35.49 and hydroxyectoine study: 38.30 ; vimentin = ectoine study: 35.49 and hydroxyectoine study: 35.74$)$. Then, lower and upper thresholds were determined (GFAP = ectoine: lower threshold: 8.98 and upper threshold: 100 and hydroxyectoine: lower threshold: 10.86 and upper threshold: 90.00 ; vimentin = ectoine: lower threshold: 3.77 and upper threshold: 100.00 and hydroxyectoine: lower threshold: 4.79 and upper threshold: 90.00). Using these thresholds, the signal area fraction per image was calculated with ImageJ. Figures of statistical analyses show the signal area fraction per image.

Fig. 2 Comparable retinal structure. (a) To detect structural changes in the retina, cross-sections were stained with hematoxylin and eosin. Retinal layers were quite intact in all groups and revealed approximately the same number of cells. (b) The total retina thickness was comparable in the four groups. (c) The thickness of the GCL was also similar in all groups. (d) No significant differences were noted in IPL thickness. (e) The only significant difference in regard to the INL was noted between ectoine and $\mathrm{CoCl}_{2}$ samples. (f) The OPL thickness was rather the same in the evaluated groups. (g) In addition, the values of the ONL measurements were comparable in this study. GCL, ganglion cell layer; IPL, inner plexiform layer; INL, inner nuclear layer; OPL, outer plexiform layer; ONL, outer nuclear layer. Each triangle depicts an individual organ culture. The horizontal bar indicates the mean per group. Scale bar $=20 \mu \mathrm{m}$. $* * p<0.01 . N=6 /$ group 


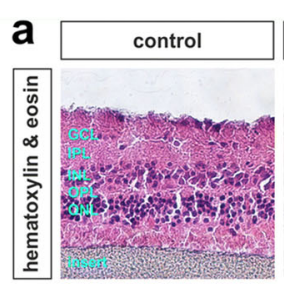

\section{b}
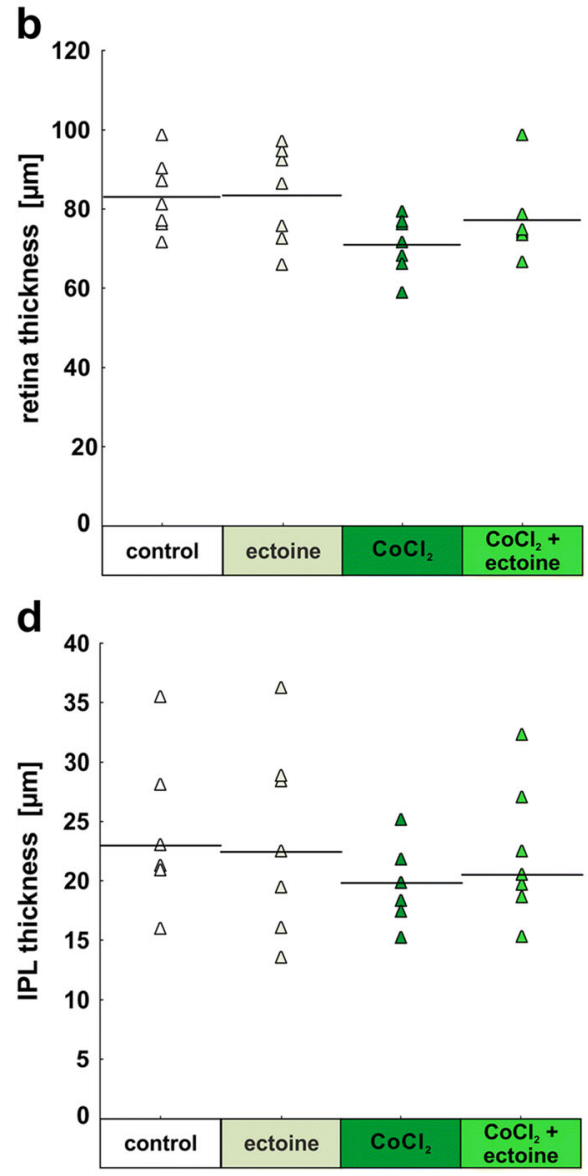

f

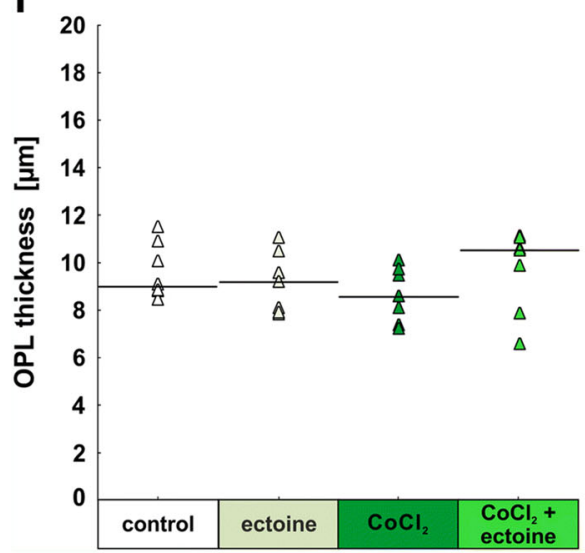

\section{Statistical analyses}

Groups were compared by one-way ANOVA, followed by post hoc Tukey HSD test (Statistica V 13; Statsoft,
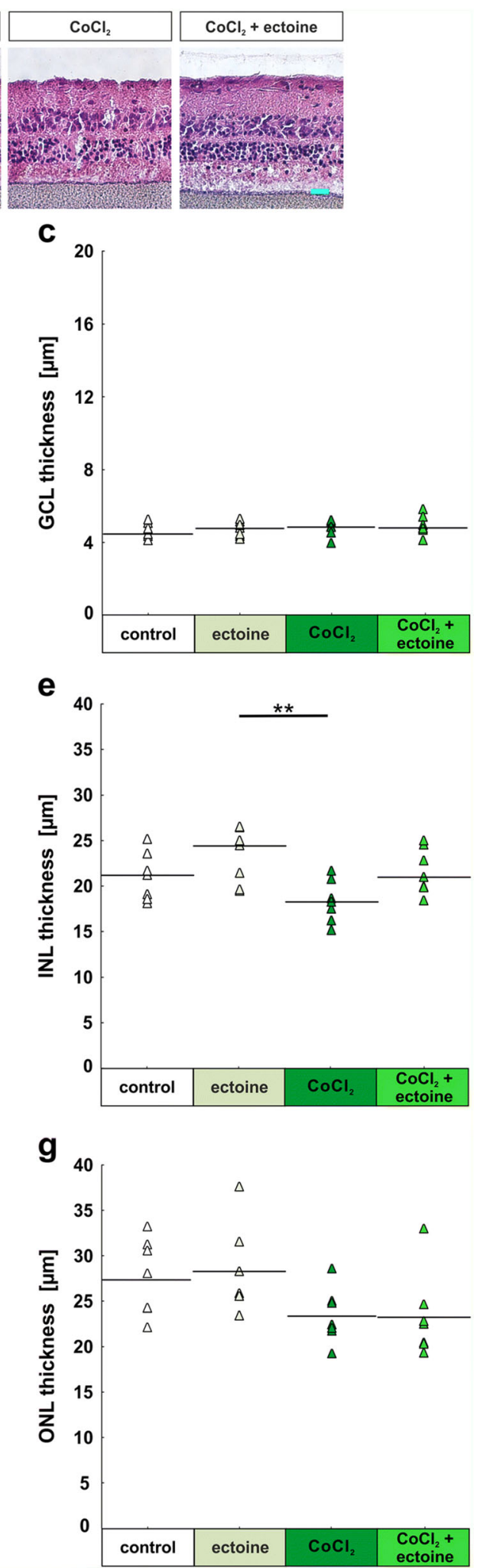

Tulsa, OK, USA). Results are presented as scatter plots with means. A $p$ value $<0.05$ was considered as statistically significant. The level of significance was set to ${ }^{*} p<0.05,{ }^{* *} p<0.01$, and $* * * p<0.001$. 

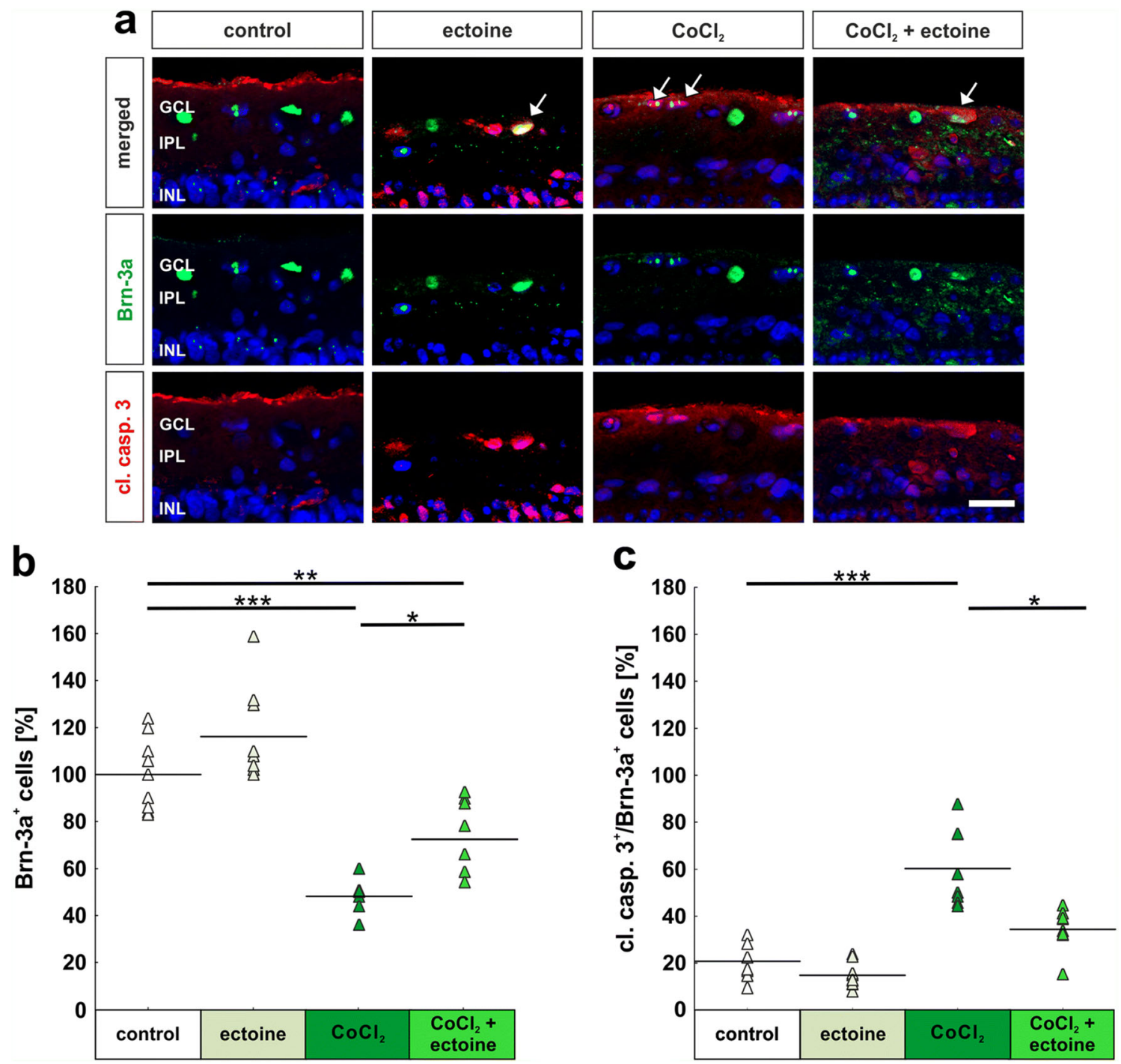

Fig. 3 Rescue of retinal ganglion cells through ectoine. (a) RGCs were stained with a specific antibody against Brn-3a (green) and additionally with cleaved caspase 3 (cl. casp. 3; red, arrows label the signal) to detect apoptotic RGCs. Cell nuclei were visualized with DAPI (blue). (b) Cell counts of Brn- $3 \mathrm{a}^{+} \mathrm{RGCs}$ revealed a significant loss through $\mathrm{CoCl}_{2}$-induced hypoxia. Interestingly, ectoine treatment protected RGCs significantly. (c)

RGCs loss in $\mathrm{CoCl}_{2}$-treated retinas was accompanied by an increased apoptosis rate, which was significantly inhibited through ectoine treatment. GCL, ganglion cell layer; IPL, inner plexiform layer; INL, inner nuclear layer. Each triangle depicts an individual organ culture. The horizontal bar indicates the mean per group. Cell counts are shown in percentage. Scale bars $=20 \mu \mathrm{m}$. $* p<0.05 ; * * p<0.01 ; * * * p<0.001 . N=8$ /group

\section{Results}

\section{Ectoine}

\section{Increased survival of retinal ganglion cells through ectoine treatment}

Hematoxylin and eosin staining can be used to investigate retinal structure. The organization of the retinal layers was not considerably altered through the cultivation or the substances, $\mathrm{CoCl}_{2}$ and ectoine, that were added (Fig. 2a). The thickness of the total retina in the control group was $83.1 \pm$

Fig. 4 No effect of ectoine on number of hypoxic cells in retinas. (a) Neurons located in the GCL were stained with NeuN (green). Hypoxic cells were visualized by specific HIF-1 $\alpha$ antibodies (red). Cell nuclei are shown in blue (DAPI). (b) $\mathrm{CoCl}_{2}$ led to an irreversible, significant increase of hypoxic cells in the total retina. Ectoine treatment did not have any inhibiting impact on the number of HIF- $1 \alpha^{+}$cells in all retinal layers. (c) Additionally, hypoxia significantly increased the number of HIF- $1 \alpha^{+}$cells in the GCL. Ectoine slightly decreased the number of hypoxic cells in the GCL. (d) Hypoxic neurons located in the GCL were evaluated by counting HIF- $1 \alpha^{+}$and $\mathrm{NeuN}^{+}$cells. The addition of $\mathrm{CoCl}_{2}$ led to a significantly increased number of hypoxic neurons in the GCL. Ectoine had no impact on the number of hypoxic neurons. GCL, ganglion cell layer; IPL, inner plexiform layer; INL, inner nuclear layer; OPL, outer plexiform layer; ONL, outer nuclear layer. Each triangle depicts an individual organ culture. The horizontal bar indicates the mean per group. Cell counts are shown in percentage. Scale bar $=20 \mu \mathrm{m} . * p<0.05 ; * * p<0.01 ; * * * p<0.001 . N=8$ /group 

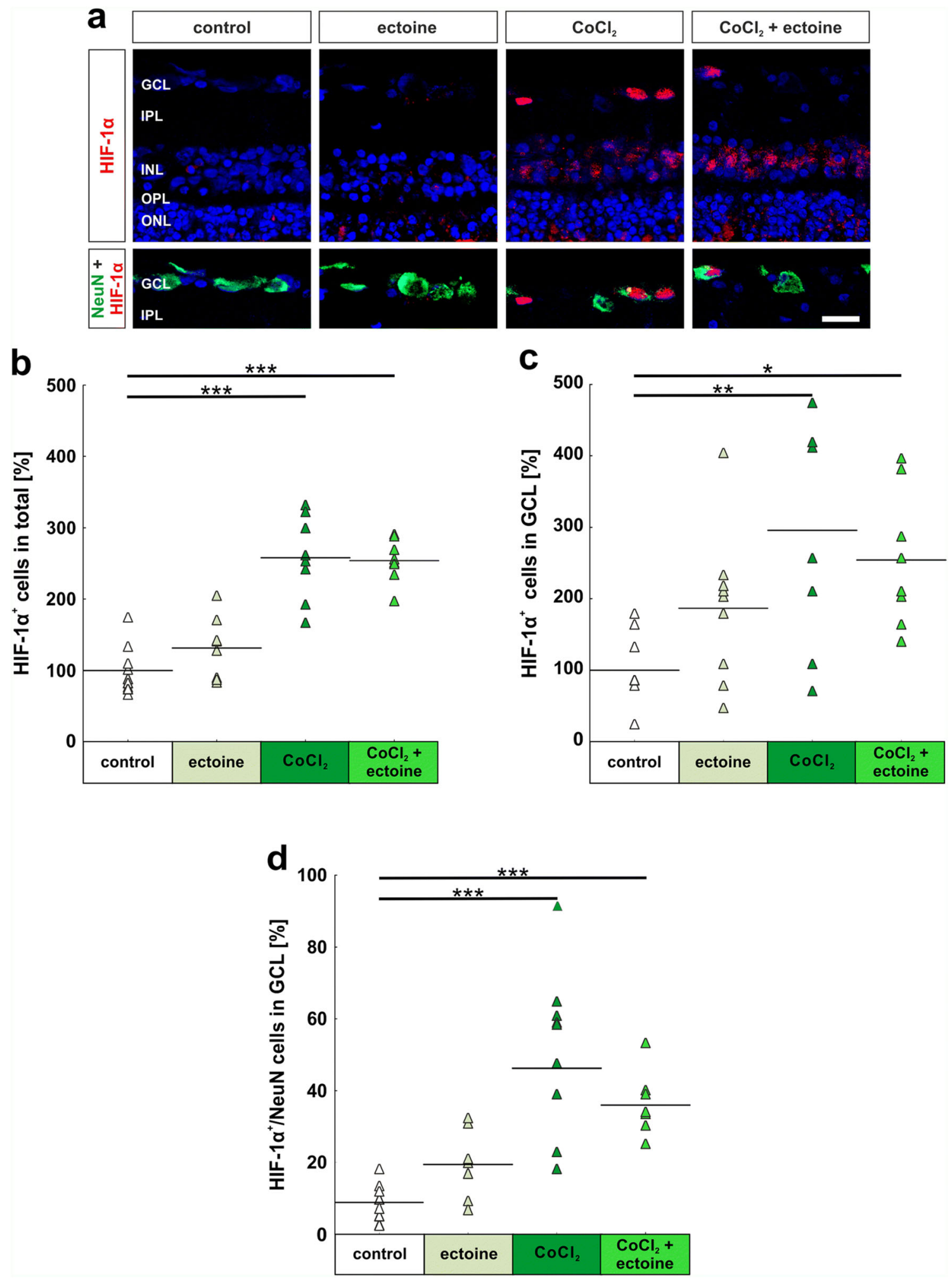

$3.6 \mu \mathrm{m}$ and $83.4 \pm 4.6 \mu \mathrm{m}$ in the ectoine group ( $p=0.99$; Fig. 2b). The retinal thickness of the $\mathrm{CoCl}_{2}(71.1 \pm 2.7 \mu \mathrm{m} ; p=$ $0.13)$ and the $\mathrm{CoCl}_{2}+$ ectoine $(77.2 \pm 3.8 \mu \mathrm{m} ; p=0.69)$ was also comparable with the control group. The GCL thickness was also similar in the ectoine $(4.7 \pm 0.4 \mu \mathrm{m} ; p=0.92)$, the
$\mathrm{CoCl}_{2}(4.7 \pm 0.4 \mu \mathrm{m} ; p=0.85)$, and the $\mathrm{CoCl}_{2}+$ ectoine group $(4.9 \pm 0.5 \mu \mathrm{m} ; p=0.51)$, when compared with the control group $(4.6 \pm 0.5 \mu \mathrm{m} ;$ Fig. $2 \mathrm{c})$. The IPL thickness in the ectoine $(23.6 \pm 3.0 \mu \mathrm{m} ; p=1.00)$, the $\mathrm{CoCl}_{2}(19.6 \pm 1.2 \mu \mathrm{m} ; p=$ $0.55)$, and the $\mathrm{CoCl}_{2}+$ ectoine $(22.3 \pm 2.2 \mu \mathrm{m} ; p=0.95)$ was 

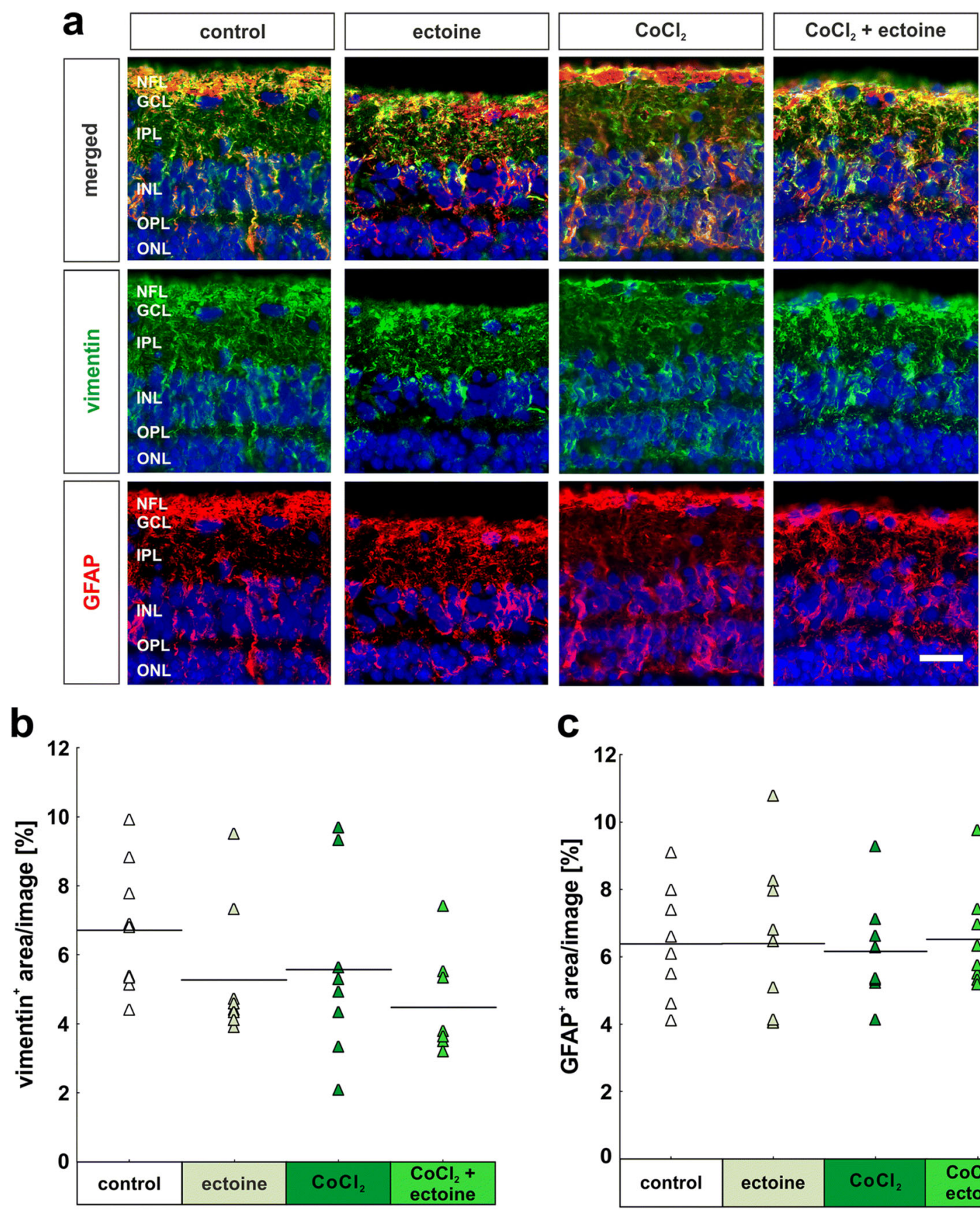

\section{C}

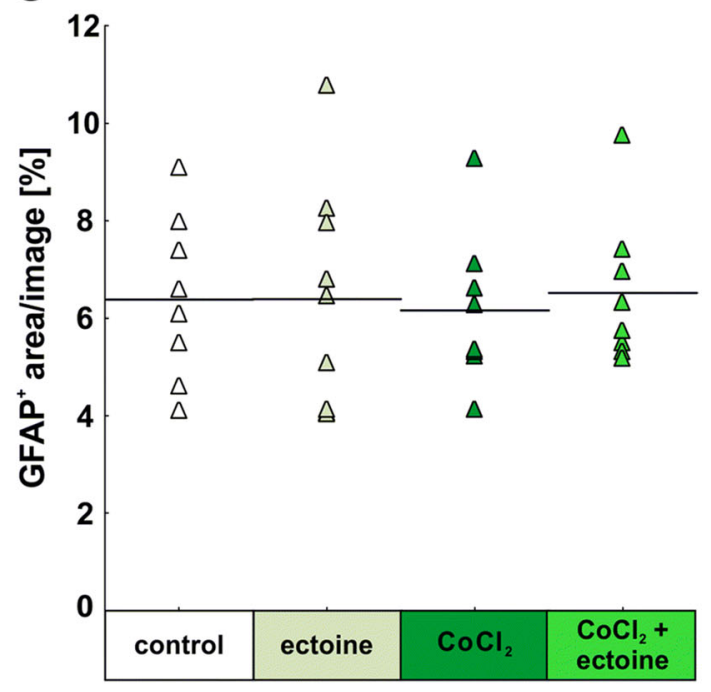

Fig. 5 No macroglial response in retinas. (a) Müller glia were stained with a vimentin antibody (green), astrocytes with a GFAP antibody (red), and cell nuclei with DAPI (blue). Double staining of GFAP and vimentin is also displayed. (b) Evaluation of vimentin ${ }^{+}$area revealed no differences within the four groups. (c) No alterations were seen comparing all groups

comparable with the control group ( $23.9 \pm 0.5 \mu \mathrm{m}$; Fig. $2 \mathrm{~d})$. No significant differences were measured between the INL thickness of the ectoine group $(23.3 \pm 1.2 \mu \mathrm{m})$ and the control group $(21.0 \pm 1.0 \mu \mathrm{m} ; p=0.4$; Fig. 2e). The INL thickness of the $\mathrm{CoCl}_{2}(18.3 \pm 0.9 \mu \mathrm{m} ; p=0.25)$ and the $\mathrm{CoCl}_{2}+$ ectoine (21.6 $\pm 1.0 \mu \mathrm{m} ; p=0.97)$ was also comparable with the control group. A significant difference was noted, when

in regard to $\mathrm{GFAP}^{+}$area. NFL, nerve fiber layer; GCL, ganglion cell layer; IPL, inner plexiform layer; INL, inner nuclear layer; OPL, outer plexiform layer; ONL, outer nuclear layer. Each triangle depicts an individual organ culture. The horizontal bar indicates the mean per group. Scale bar $=20 \mu \mathrm{m} . N=8 /$ group

comparing the INL thickness of ectoine and $\mathrm{CoCl}_{2}$ samples $(p=0.009)$. OPL thickness in the ectoine $(9.2 \pm 0.49 \mu \mathrm{m} ; p=$ $0.90)$, the $\mathrm{CoCl}_{2}(8.6 \pm 1.2 \mu \mathrm{m} ; p=0.52)$, and the $\mathrm{CoCl}_{2}+$ ectoine $(9.7 \pm 0.7 \mu \mathrm{m} ; p=1.00)$ was comparable with the control group $(9.7 \pm 0.5 \mu \mathrm{m}$; Fig. $2 \mathrm{f})$. In regard to the ONL layer thickness, no significant differences were noted between any of the groups. Control samples had a mean ONL layer 
thickness of $27.3 \pm 1.7 \mu \mathrm{m}$, ectoine samples of $28.3 \pm 1.8 \mu \mathrm{m}$ ( $p=0.98), \mathrm{CoCl}_{2}$ of $23.4 \pm 1.1 \mu \mathrm{m}(p=0.34)$, and $\mathrm{CoCl}_{2}+$ ectoine of $23.3 \pm 1.1 \mu \mathrm{m}$ ( $p=0.31$; Fig. $2 \mathrm{~g})$.

To investigate the effects of ectoine on RGCs and their apoptosis rate, a double staining with anti-Brn-3a and anticleaved caspase 3-antibodies was performed (Fig. 3a). Cell counts of Brn- $3 \mathrm{a}^{+}$RGCs revealed no differences between the control group $\left(100.0 \% \pm 5.2 \% \mathrm{Brn}-3 \mathrm{a}^{+}\right.$cells $)$and the ones treated with just ectoine $\left(116.2 \% \pm 6.6 \%\right.$ Brn- $3 \mathrm{a}^{+}$cells; $p=$ $0.15)$. In contrast, hypoxia induced a prominent loss of around $50 \%$ of RGCs in the $\mathrm{CoCl}_{2}$ group $\left(48.2 \% \pm 2.4 \%\right.$ Brn- $3 \mathrm{a}^{+}$ cells; $p=0.0002$ ) even though the number of RGCs counted in the $\mathrm{CoCl}_{2}+$ ectoine group $\left(72.47 \% \pm 5.83 \% \mathrm{Brn}-3 \mathrm{a}^{+}\right.$cells $)$ was significantly lower than in the control group $(p=0.007)$. Moreover, ectoine led to a significant rescue of nearly $24 \%$ in comparison with the $\mathrm{CoCl}_{2}$ group ( $p=0.02$; Fig. $3 b$ ).

Results regarding apoptosis showed that the degenerative effect of $\mathrm{CoCl}_{2}$ is not limited to neurons of the ganglion cell layer, but occurred across all retinal layers. The results of the apoptosis rate of RGCs were consistent with those of the RGC counting (Fig. 3c). No differences were noted between the control $\left(20.8 \% \pm 2.7 \%\right.$ cleaved caspase $3^{+}$and $\mathrm{Brn}-3 \mathrm{a}^{+}$cells $)$ and the ectoine group $\left(14.8 \% \pm 1.7 \%\right.$ cleaved caspase $3^{+}$and Brn-3a ${ }^{+}$cells; $p=0.62$ ). The addition of $\mathrm{CoCl}_{2}$ induced apoptotic processes in RGCs and led to a significant increase of nearly $40 \%$ of apoptotic RGCs $(60.4 \% \pm 5.9 \%$ cleaved caspase $3^{+}$and $\mathrm{Brn}-3 \mathrm{a}^{+}$cells; $p=0.0002$ ). Interestingly, the treatment with ectoine clearly prevented apoptosis of some RGCs $\left(34.4 \% \pm 3.2 \%\right.$ cleaved caspase $3^{+}$and Brn- $3 \mathrm{a}^{+}$cells; $p=$ 0.0003 ) in comparison with the $\mathrm{CoCl}_{2}$ group. Hardly, any differences were noted between the control and the $\mathrm{CoCl}_{2}+$ ectoine group regarding apoptotic RGCs ( $p=0.06$; Fig. $3 \mathrm{c}$ ).

\section{No effects of ectoine on the hypoxic stage of the retina}

A hallmark for oxidative stress is the stabilization of the transcription factor HIF- $1 \alpha$. To evaluate the hypoxic state of the retina, we performed immunohistochemical double staining using NeuN, a neuronal marker, for cells located in the GCL and HIF- $1 \alpha$ as a marker for hypoxic cells (Fig. 4a). HIF- $1 \alpha^{+}$cells in all retinal layers (Fig. 4b), HIF- $1 \alpha^{+}$cells located in the GCL (Fig. 4c), and also HIF- $1 \alpha^{+}$and $\mathrm{NeuN}^{+}$colocalized cells in the GCL (Fig. 4d) were evaluated.

Ectoine solely had no effect on the amount of HIF- $1 \alpha^{+}$ cells in the total retina (control: $100.0 \% \pm 11.6 \%$ HIF- $1 \alpha^{+}$ cells; ectoine: $131.6 \% \pm 13.6 \%$ HIF- $1 \alpha^{+}$cells; $p=0.40$ ). In contrast, $\mathrm{CoCl}_{2}$ led in both stressed groups to a significantly increased number of HIF- $1 \alpha^{+}$cells in comparison with control retinas $\left(\mathrm{CoCl}_{2}: 257.9 \% \pm 20.8 \% \mathrm{HIF}-1 \alpha^{+}\right.$cells; $p=0.0002 ; \mathrm{CoCl}_{2}+$ ectoine: $253.9 \% \pm 10.7 \%$ HIF- $1 \alpha^{+}$ cells; $p=0.0002$ ). Interestingly, ectoine had an effect on the hypoxic state of the cells, since no statistical differences were noted between the $\mathrm{CoCl}_{2}+$ ectoine and the $\mathrm{CoCl}_{2}$ group ( $p=0.99$; Fig. $4 \mathrm{~b}$ ). In regard to the number of HIF- $1 \alpha^{+}$cells located in the GCL, the ectoine group $\left(186.2 \% \pm 35.1 \%\right.$ HIF- $1 \alpha^{+}$cells $)$had nearly twice high HIF- $1 \alpha^{+}$cell counts as the control group $(100.0 \% \pm$ $18.6 \%$ HIF- $1 \alpha^{+}$cells), but no statistical difference was seen between those two groups $(p=0.34) . \mathrm{CoCl}_{2}$-stressed retinas exhibited significantly more hypoxic HIF- $1 \alpha^{+}$cells in the GCL $\left(\mathrm{CoCl}_{2}: 295.8 \% \pm 55.1 \%\right.$ HIF- $1 \alpha^{+}$cells; $p=$ 0.005; $\mathrm{CoCl}_{2}+$ ectoine: $254.1 \% \pm 33.6 \% \mathrm{HIF}-1 \alpha^{+}$cells; $p=0.036)$ than the control group. Even though retinas from the $\mathrm{CoCl}_{2}+$ ectoine group had slightly fewer HIF$1 \alpha^{+}$cells than the solely $\mathrm{CoCl}_{2}$ group, no differences were seen comparing both groups ( $p=0.86$; Fig. $4 c$ ). Similar results as described before were seen when evaluating the number of hypoxic neurons, which were HIF- $1 \alpha^{+}$and $\mathrm{NeuN}^{+}$. Comparing the control $\left(8.8 \% \pm 1.7 \%\right.$ HIF- $1 \alpha^{+}$ and $\mathrm{NeuN}^{+}$cells) and ectoine group $(19.4 \% \pm 2.8 \%$ HIF$1 \alpha^{+}$and $\mathrm{NeuN}^{+}$cells), no differences were noted $(p=$ 0.18 ), whereas the addition of $\mathrm{CoCl}_{2}$ strongly increased the amount of hypoxic cells in the $\mathrm{CoCl}_{2}$ group $(46.2 \% \pm$ $6.4 \% \mathrm{HIF}-1 \alpha^{+}$and NeuN ${ }^{+}$cells; $\left.p=0.0002\right)$ as well as in the $\mathrm{CoCl}_{2}+$ ectoine group $\left(35.9 \% \pm 3.0 \%\right.$ HIF- $1 \alpha^{+}$and $\mathrm{NeuN}^{+}$cells; $p=0.0003$ ). Again, ectoine had no lowering effect on the number of hypoxic neurons in comparison with the $\mathrm{CoCl}_{2}$ group ( $p=0.25$; Fig. $\left.4 \mathrm{~d}\right)$.

\section{Absence of macroglial response in porcine retinas}

Two important glial cell types of the retina are Müller cells and astrocytes. Müller cells span across the whole retina and are crucial for its health. They can be visualized using a vimentin antibody (Fig. 5a). Astrocytes, in contrast, are the main producer of glial fibrillary acidic protein (GFAP), a protein which is highly expressed in injured or diseased retinas. To investigate both cell types, retinal crosssections were double stained using vimentin and GFAP antibodies. Exemplary images show the localization of both cell types, which are spanning across the retina. Interestingly, vimentin and GFAP appear to be mainly co-localized in the retina (Fig. 5a). Nevertheless, the immunoreactivities of both markers were analyzed individually.

The immunoreactivity of vimentin was comparable within all investigated groups (Fig. 5b). Neither solely ectoine $\left(5.3 \% \pm 0.6 \%\right.$ vimentin $^{+}$area; $\left.p=0.44\right), \mathrm{CoCl}_{2}$ $\left(5.6 \% \pm 1.0 \%\right.$ vimentin ${ }^{+}$area; $\left.p=0.67\right)$, nor $\mathrm{CoCl}_{2}+$ ectoine $\left(4.5 \% \pm 0.5 \%\right.$ vimentin $^{+}$area; $\left.p=0.14\right)$ had any effects on the vimentin ${ }^{+}$area in these retinas compared with control ones $\left(6.7 \% \pm 0.6 \%\right.$ vimentin $^{+}$area; Fig. 5b).

No differences regarding the $\mathrm{GFAP}^{+}$area were seen within the groups (Fig. $5 \mathrm{c}$ ). The immunoreactivity of GFAP in the 

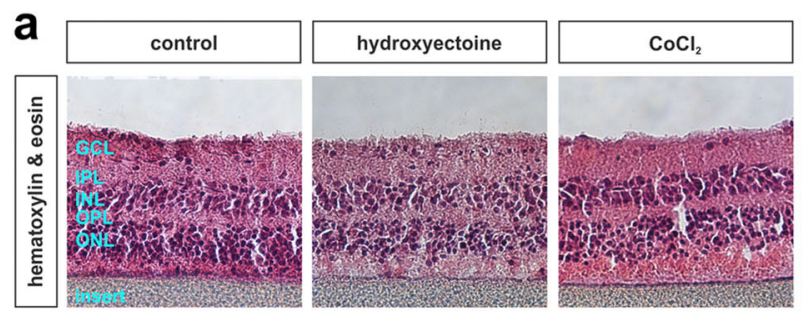

$\mathrm{CoCl}_{2}+$ hydroxyectoine
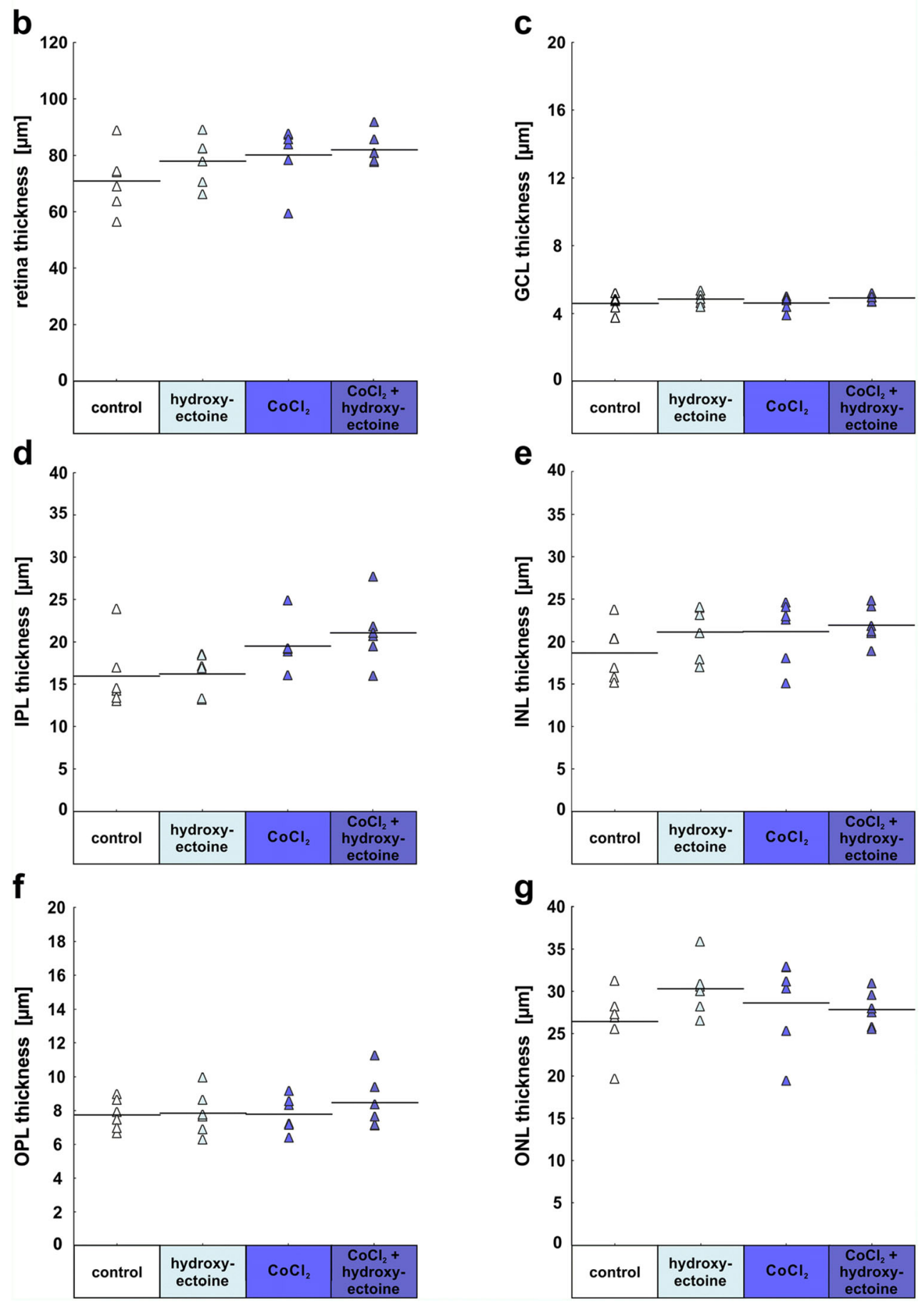
Fig. 6 Retinal layers remain intact. (a) For an overview of retinal structure, hematoxylin and eosin staining was performed. Retinas of all groups remained intact during cultivation. (b) The total retinal thickness was similar in all groups. (c) No significant differences were noted in the GCL thickness between all analyzed groups. (d) The IPL thickness was also similar in all groups. (e) With regard to the ONL thickness, all groups have almost the same measured values. (f) The OPL thickness was rather the same in the evaluated groups. (g) In addition, the values of the ONL measurements were comparable in this study. GCL, ganglion cell layer; IPL, inner plexiform layer; INL, inner nuclear layer; OPL, outer plexiform layer; ONL, outer nuclear layer. Each triangle depicts an individual organ culture. The horizontal bar indicates the mean per group. Scale bar $=20 \mu \mathrm{m} . N=6 /$ group

control group $\left(6.4 \% \pm 0.2 \mathrm{GFAP}^{+}\right.$area $)$was not altered in comparison with the ectoine group $\left(6.4 \% \pm 0.8 \% \mathrm{GFAP}^{+}\right.$area; $p=1.00)$, the $\mathrm{CoCl}_{2}$ group $\left(6.2 \% \pm 0.6 \% \mathrm{GFAP}^{+}\right.$area; $p=$ $0.99)$, and the $\mathrm{CoCl}_{2}+$ ectoine group $\left(6.5 \% \pm 0.5 \% \mathrm{GFAP}^{+}\right.$ area; $p=1.00$; Fig. 5c).

\section{Hydroxyectoine}

\section{Retinal ganglion cell rescue and decreased apoptosis rate due to hydroxyectoine}

To analyze the possible protective effects of hydroxyectoine, the second extremolyte we tested, we again performed H\&E staining to evaluate the integrity of the retina. In all four groups, the different retinal layers were well separated and identifiable, which indicated that the morphological integrity was given in all of the investigated retinas (Fig. 6a). In regard to the total retinal thickness, it was comparable in the control $(70.9 \pm 4.5)$, the hydroxyectoine $(77.9 \pm 3.4 ; p=0.56)$, the $\mathrm{CoCl}_{2}(80.1 \pm 4.4 ; p=0.33)$, and the $\mathrm{CoCl}_{2}+$ hydroxyectoine group (81.8 $\pm 2.3 ; p=0.20$; Fig. $6 \mathrm{~b})$. The GCL thickness in the hydroxyectoine $(4.8 \pm 0.1 ; p=0.64)$, the $\mathrm{CoCl}_{2}(4.6 \pm 0.2$; $p=1.0)$, and the $\mathrm{CoCl}_{2}+$ hydroxyectoine group $(4.9 \pm 0.1$; $p=0.45$ ) was not significantly different from control samples (4.6 \pm 0.2 ; Fig. $6 \mathrm{c})$. In regard to the IPL thickness, no significant differences were noted between any of the groups. Control samples had a mean IPL layer thickness of $16.1 \pm$ $1.7 \mu \mathrm{m}$, hydroxyectoine samples of $16.3 \pm 1.0 \mu \mathrm{m}(p=$ $1.00), \mathrm{CoCl}_{2}$ of $19.6 \pm 1.2 \mu \mathrm{m}(p=0.29)$, and $\mathrm{CoCl}_{2}+$ hydroxyectoine of $21.2 \pm 1.6 \mu \mathrm{m}(p=0.07$; Fig. $6 \mathrm{~d})$. Moreover, no significant differences were measured between the INL thickness of the hydroxyectoine group $(21.1 \pm$ $1.3 \mu \mathrm{m})$ and the control group $(18.7 \pm 1.4 \mu \mathrm{m} ; p=0.54$; Fig. 2e). The INL thickness of the $\mathrm{CoCl}_{2}(21.2 \pm 1.5 \mu \mathrm{m} ; p=0.52)$ and the $\mathrm{CoCl}_{2}+$ hydroxyectoine $(21.9 \pm 0.9 \mu \mathrm{m} ; p=0.30)$ were also comparable with the control group. In regard to the OPL layer thickness, no significant differences were noted between any of the groups. Control samples had a mean OPL layer thickness of $7.7 \pm 10.4 \mu \mathrm{m}$, hydroxyectoine samples of
$7.8 \pm 0.5 \mu \mathrm{m}(p=1.0), \mathrm{CoCl}_{2}$ of $7.8 \pm 0.4 \mu \mathrm{m}(p=1.0)$, and $\mathrm{CoCl}_{2}+$ hydroxyectoine of $8.5 \pm 0.7 \mu \mathrm{m}(p=0.74$; Fig. $6 \mathrm{f})$. The ONL thickness in the hydroxyectoine $(30.2 \pm 1.3 \mu \mathrm{m} ; p=$ $0.31)$, the $\mathrm{CoCl}_{2}(28.6 \pm 2.2 \mu \mathrm{m} ; p=0.75)$, and the $\mathrm{CoCl}_{2}+$ hydroxyectoine $(27.8 \pm 0.9 \mu \mathrm{m} ; p=0.91)$ was again comparable with the control group $(26.4 \pm 1.6 \mu \mathrm{m}$; Fig. $6 \mathrm{f})$.

RGCs and their apoptosis rate were analyzed immunohistochemically by specific antibodies Brn-3a and cleaved caspase 3 (Fig. 7a). Brn- $3 \mathrm{a}^{+}$cell numbers indicated a significant RGC loss just by adding hydroxyectoine to the medium (control: $100.0 \% \pm 3.6 \% \mathrm{Brn}^{-} 3 \mathrm{a}^{+}$cells; hydroxyectoine: $69.7 \% \pm 3.8 \%$ Brn- $3 \mathrm{a}^{+}$cells; $p=0.0002$ ). The loss of RGCs due to $\mathrm{CoCl}_{2}$ was even more prominent $\left(28.0 \% \pm 1.3 \% \mathrm{Brn}-3 \mathrm{a}^{+}\right.$cells; $\left.p=0.0002\right)$, which was significantly lowered by hydroxyectoine $\left(\mathrm{CoCl}_{2}+\right.$ hydroxyectoine: $44.9 \% \pm 3.0 \% \mathrm{Brn}^{-3 \mathrm{a}^{+}}$cells; $\left.p=0.003\right)$. Even though a rescue effect by hydroxyectoine of around $16 \%$ was seen in $\mathrm{CoCl}_{2}+$ hydroxyectoine retinas in comparison with $\mathrm{CoCl}_{2}$ ones, retinas treated with $\mathrm{CoCl}_{2}+$ hydroxyectoine still exhibited significantly fewer RGCs than the control group ( $p=0.0002$; Fig. 7b).

Results regarding apoptosis showed that the degenerative effect of $\mathrm{CoCl}_{2}$ is not limited to neurons of the ganglion cell layer but occurs across all retinal layers. Despite the prominent loss of RGCs, no differences were seen in regard to the apoptosis rate when comparing the control group $\left(21.4 \% \pm 3.1 \%\right.$ cleaved caspase $3^{+}$and Brn- $3 \mathrm{a}^{+}$cells $)$and the hydroxyectoine group $(24.6 \% \pm$ $1.7 \%$ cleaved caspase $3^{+}$and $\mathrm{Brn}-3 \mathrm{a}^{+}$cells; $p=0.83$ ). However, the loss of $\mathrm{RGCs}$ in $\mathrm{CoCl}_{2}$-treated retinas seemed to be provoked by apoptosis, since the apoptosis rate was twice as higher than in control ones $(52.1 \% \pm$ $2.1 \%$ cleaved caspase $3^{+}$and Brn- $3 \mathrm{a}^{+}$cells; $p=0.0002$ ). Hydroxyectoine treatment had a strong effect on the apoptosis rate and lowered it significantly in comparison with the $\mathrm{CoCl}_{2}$ group $(34.5 \% \pm 3.5 \%$ cleaved caspase $3^{+}$and $\left.\mathrm{Brn}-3 \mathrm{a}^{+} ; p=0.0006\right)$, but it was still higher than in control retinas $(p=0.009$; Fig. $7 \mathrm{c})$.

\section{Reduced hypoxic processes in the retina after hydroxyectoine treatment}

To investigate the effects of hydroxyectoine on hypoxia, retinal cross-sections were stained with specific NeuN and HIF- $1 \alpha$ antibodies (Fig. 8a). The application of hydroxyectoine had no effect on the amount of HIF$1 \alpha^{+}$cells in all retinal layers (control: $100.0 \% \pm 11.7 \%$ HIF- $1 \alpha^{+}$cells; hydroxyectoine: $128.3 \% \pm 7.8 \%$ HIF- $1 \alpha^{+}$ cells; $p=0.12$ ). In contrast, $\mathrm{CoCl}_{2}$ retinas without any additional treatment had three times more HIF- $1 \alpha^{+}$cells than control ones $\left(326.6 \% \pm 6.5 \%\right.$ HIF- $1 \alpha^{+}$cells; $p=$ $0.0002)$. Hydroxyectoine treatment lowered the stabilization of HIF- $1 \alpha$ in retinal cells in comparison with the 

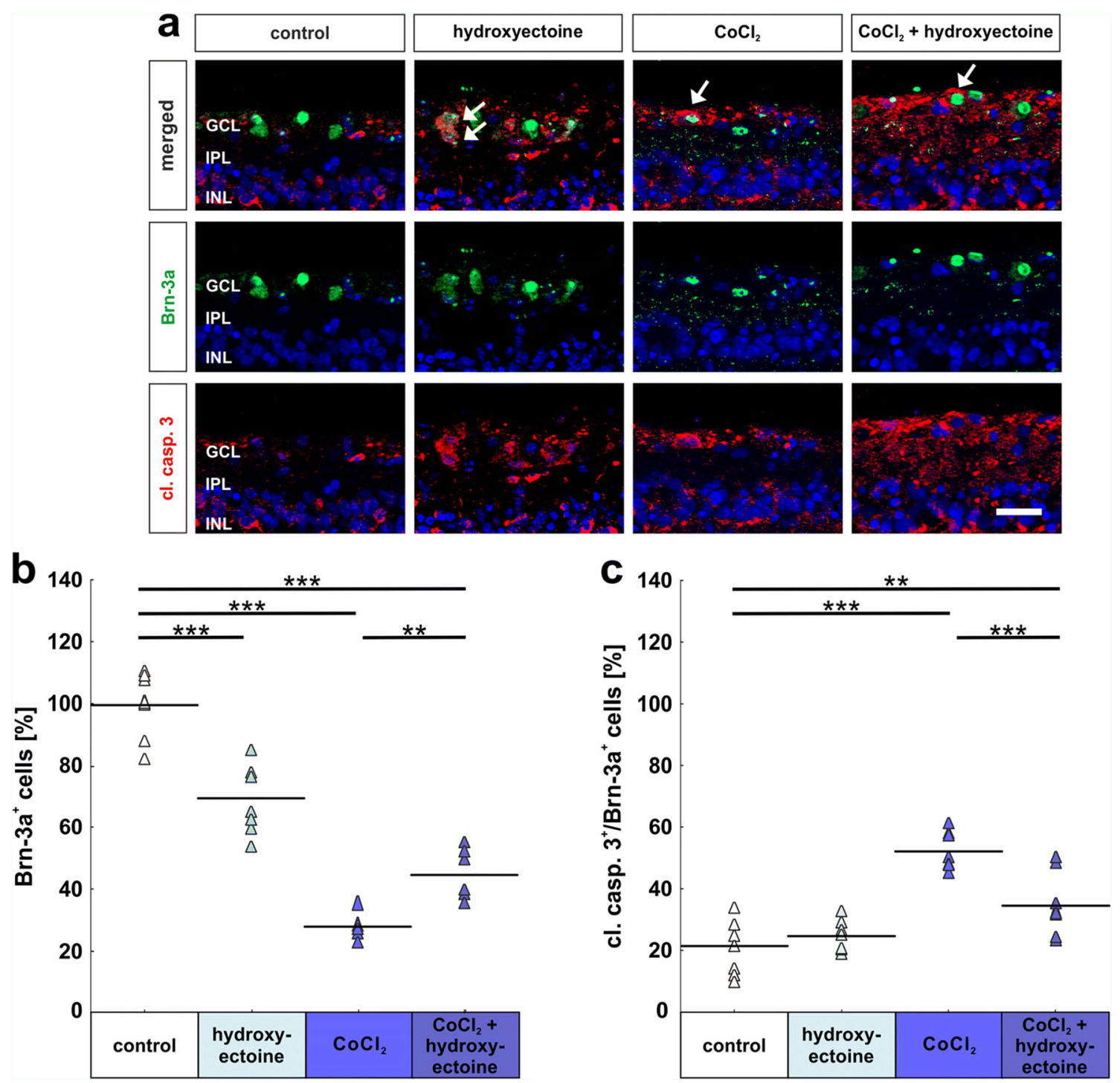

Fig. 7 Hydroxyectoine protected retinal ganglion cells by inhibiting apoptosis. (a) Brn-3a antibodies were used to label RGCs (green). To visualize apoptotic RGCs, cleaved caspase 3 (cl. casp. 3, red, arrows label the signal) antibody was additionally applied. Cell nuclei were stained with DAPI (blue). (b) Again, $\mathrm{CoCl}_{2}$-induced hypoxia led to a significant loss of RGCs. Hydroxyectoine treatment strongly lowered this impact and led to a rescue of RGCs. (c) In accordance, RGC loss

$\mathrm{CoCl}_{2}$ group $(p=0.048)$, but $\mathrm{CoCl}_{2}+$ hydroxyectoinetreated retinas still had more HIF-1a $\mathrm{a}^{+}$cells than control ones $\left(292.8 \% \pm 7.8 \%\right.$ HIF- $1 \alpha^{+}$cells; $p=0.0002$; Fig. $\left.8 b\right)$. Hypoxic cells located in the GCL showed similar results as the ones in the total retina, hydroxyectoine alone had no effects on HIF- $1 \alpha$ (control: $100.0 \pm 12.2$ HIF- $1 \alpha^{+}$ cells [\%]; hydroxyectoine: $120.6 \% \pm 13.4 \%$ HIF- $1 \alpha^{+}$ cells; $p=0.89$ ); $\mathrm{CoCl}_{2}$, irrespective of additional treatment, led to a significant increase in the number of HIF- $1 \alpha^{+}$cells $\left(\mathrm{CoCl}_{2}: 323.8 \% \pm 26.8 \%\right.$ HIF- $1 \alpha^{+}$cells; $p=0.0002 ; \mathrm{CoCl}_{2}+$ hydroxyectoine: $251.9 \% \pm 25.6 \%$ HIF- $1 \alpha^{+}$cells; $\left.p=0.0002\right)$. The statistical evaluation

due to $\mathrm{CoCl}_{2}$ was accompanied by an increased apoptosis rate, which was significantly inhibited by hydroxyectoine. GCL, ganglion cell layer; IPL, inner plexiform layer; INL, inner nuclear layer. Each triangle depicts an individual organ culture. The horizontal bar indicates the mean per group. Cell counts are shown in percentage. Scale bars $=20 \mu \mathrm{m}$. $* * p<0.01$; $* * * p<0.001 . N=8 /$ group

Fig. 8 Reduction of hypoxia in retinas through hydroxyectoine. (a) Immunohistochemical staining of hypoxic neurons located in the retina was performed by NeuN (green) and HIF-1 $\alpha$ (red) antibodies. Cell nuclei were visualized with DAPI and are shown in blue. (b) The amount of HIF-1 $\alpha^{+}$ cells in the total retina was significantly increased due to the $\mathrm{CoCl}_{2}$-stressor. Hydroxyectoine led to a significantly decreased number of hypoxic cells in the retina. (c) Even if the effect of hydroxyectoine on hypoxic cells in the GCL was not as strong for the total retina, there was still a slight reduction of hypoxic cells after the treatment. (d) Also, the number of hypoxic neurons located in the GCL was strongly reduced through hydroxyectoine. GCL, ganglion cell layer; IPL, inner plexiform layer; INL, inner nuclear layer; OPL, outer plexiform layer; ONL, outer nuclear layer. Each triangle depicts an individual organ culture. The horizontal bar indicates the mean per group. Cell counts are shown in percentage. Scale bar $=20 \mu \mathrm{m} .{ }^{*} p<0.05$; $* * p<0.01 ; * * * p<0.001 . N=8$ /group 

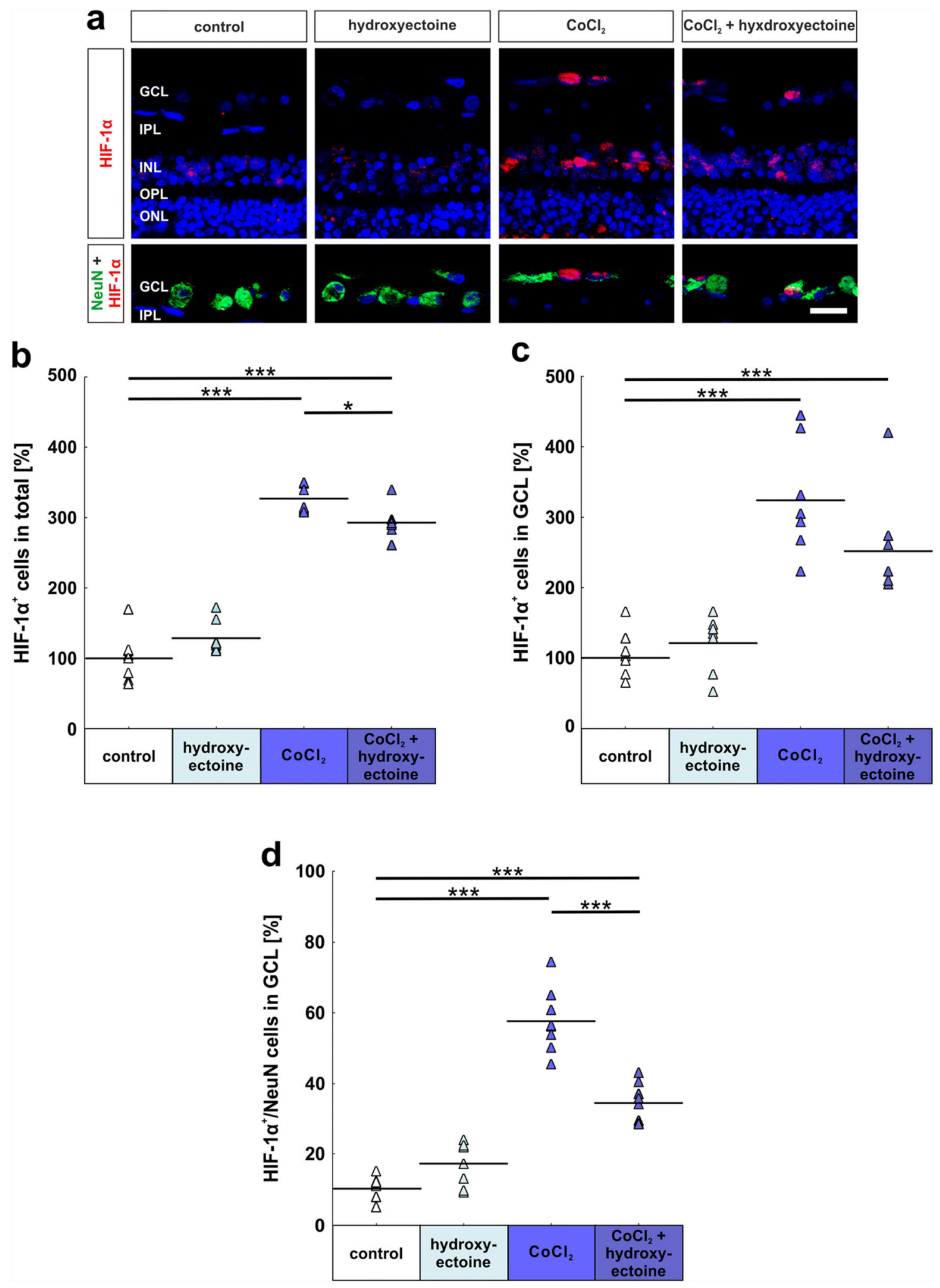

showed that hydroxyectoine had no positive effect on the amount of HIF- $1 \alpha^{+}$cells located in the GCL in comparison with $\mathrm{CoCl}_{2}$-treated retinas $(p=0.09$; Fig. 8c). Regarding the number of hypoxic $\mathrm{NeuN}^{+}$cells in the
GCL, the effects of hydroxyectoine were more notable. Control and hydroxyectoine retinas displayed a similar number of HIF- $1 \alpha^{+}$and $\mathrm{NeuN}^{+}$cells (control: $10.1 \% \pm$ $1.2 \%$ HIF- $1 \alpha^{+}$and $\mathrm{NeuN}^{+}$cells; hydroxyectoine: $17.2 \%$ 
a

a
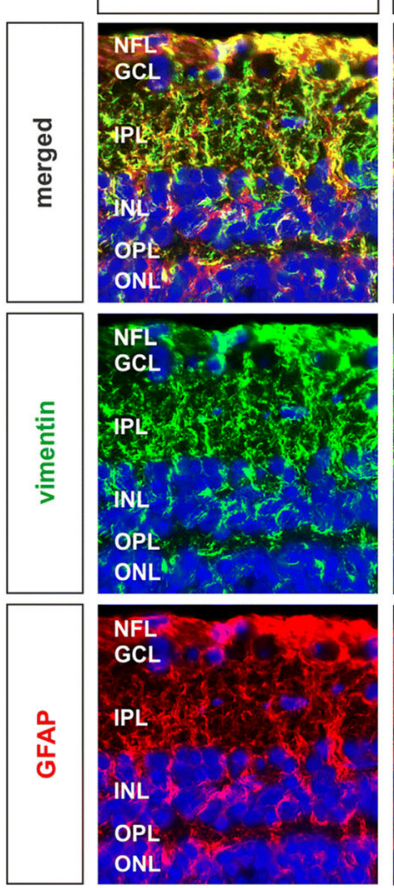

ONL
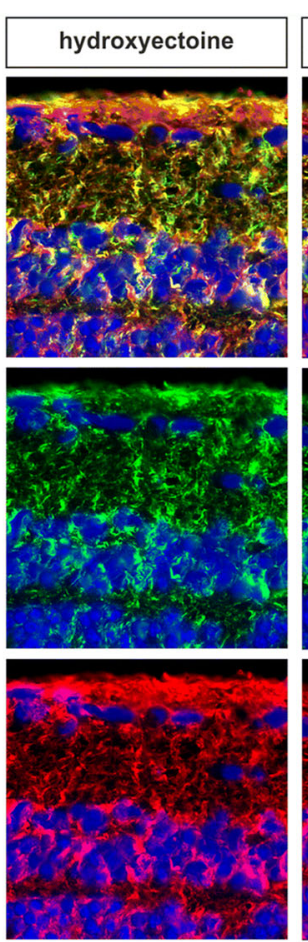
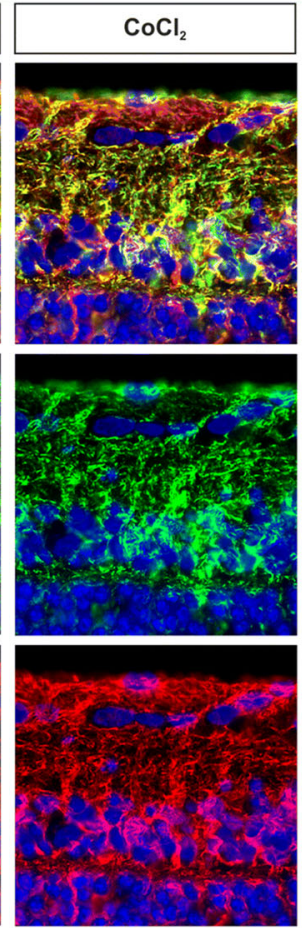
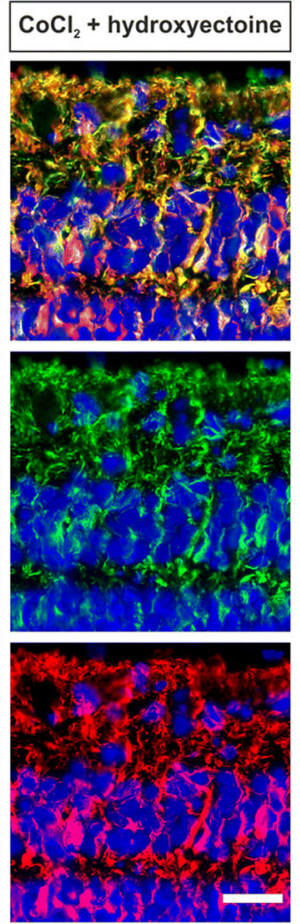

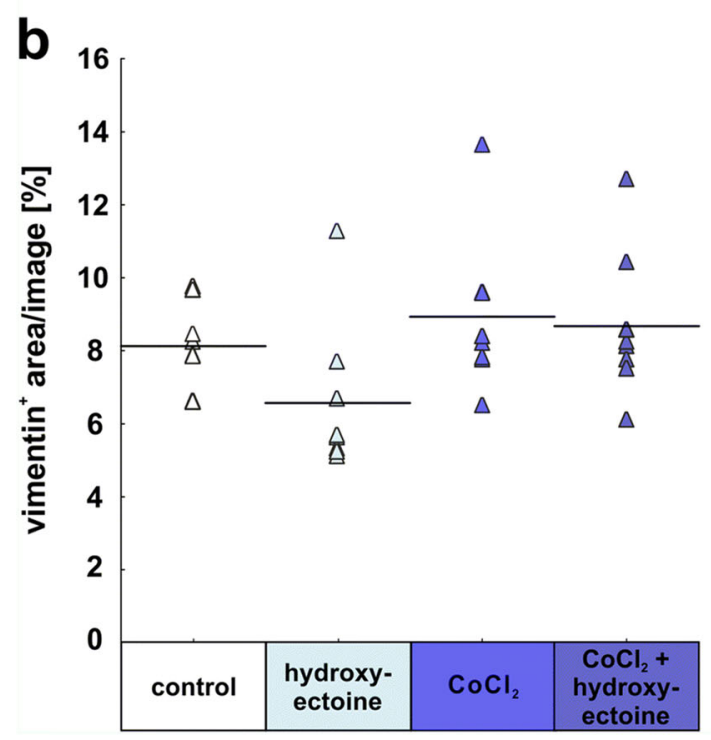

Fig. 9 Macroglial response remained unaltered. (a) To visualize Müller glia and astrocytes, cross-sections were stained immunohistochemically using vimentin (green) and GFAP (red) individually and as a double staining. Cell nuclei are shown in blue (DAPI). (b) Analyses of vimentin $^{+}$area revealed no alterations within any of the groups. (c) Neither $\mathrm{CoCl}_{2}$ nor hydroxyectoine had any effects on GFAP signal area

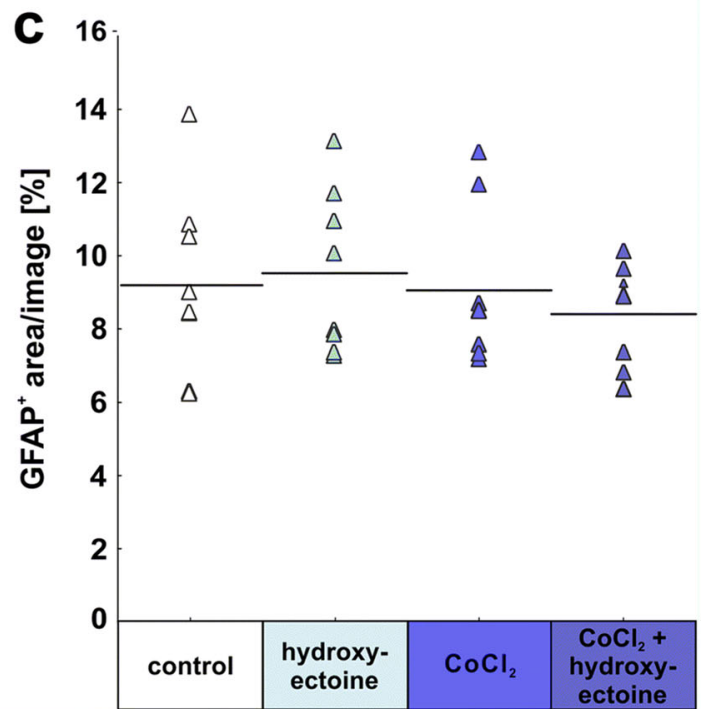

in retinas. NFL, nerve fiber layer; GCL, ganglion cell layer; IPL, inner plexiform layer; INL, inner nuclear layer; OPL, outer plexiform layer; ONL, outer nuclear layer. Each triangle depicts an individual organ culture. The horizontal bar indicates the mean per group. Scale bar $=$ $20 \mu \mathrm{m} . N=8 /$ group

$\left(34.4 \% \pm 2.0 \% \mathrm{HIF}-1 \alpha^{+}\right.$and $\mathrm{NeuN}^{+}$cells; $\left.\mathrm{p}=0.0002\right)$. Nevertheless, a protective effect of hydroxyectoine was observed, since hydroxyectoine and $\mathrm{CoCl}_{2}$-treated retinas had significantly fewer neurons in a hypoxic state than $\mathrm{CoCl}_{2}$ alone ( $p=0.0002$; Fig. $\left.8 \mathrm{~d}\right)$. 


\section{No macroglial response}

Müller cells and astrocytes were investigated immunohistochemically by a double staining using vimentin and GFAP antibodies. Co-localization, namely vimentin and $\mathrm{GFAP}^{+}$area, appears in yellow. Interestingly, a very high proportion of vimentin ${ }^{+}$area is also $\mathrm{GFAP}^{+}$. Morphology and localization of labeled cells by these markers seem to be very similar. To investigate the macroglial response, vimentin and GFAP were analyzed individually (Fig. 9a). The vimentin ${ }^{+}$area was not altered by any of the substances that were added to the medium. Neither hydroxyectoine solely $\left(6.6 \% \pm 0.7 \%\right.$ vimentin ${ }^{+}$area; $\left.p=0.38\right)$ nor $\mathrm{CoCl}_{2}$ $\left(8.9 \% \pm 0.8 \%\right.$ vimentin ${ }^{+}$area; $\left.p=0.83\right)$ or $\mathrm{CoCl}_{2}+$ hydroxyectoine $\left(8.7 \% \pm 0.7 \%\right.$ vimentin $^{+}$area; $\left.p=0.93\right)$ had any impact on Müller cells compared with controls $\left(8.1 \% \pm 0.4 \%\right.$ vimentin $^{+}$area; Fig. $\left.9 b\right)$.

Also, the astrocytes expressing GFAP were not affected in any of the groups. The GFAP ${ }^{+}$area was similar in the control $\left(9.2 \% \pm 0.9 \% \mathrm{GFAP}^{+}\right.$area $)$, the hydroxyectoine $(9.5 \% \pm 0.8 \%$ $\mathrm{GFAP}^{+}$area; $\left.p=0.99\right)$, the $\mathrm{CoCl}_{2}\left(9.1 \% \pm 0.8 \% \mathrm{GFAP}^{+}\right.$area; $p=1.0)$, and in the $\mathrm{CoCl}_{2}+$ hydroxyectoine group $(8.4 \% \pm$ $0.5 \% \mathrm{GFAP}^{+}$area; $p=0.88$; Fig. $9 \mathrm{c}$ ).

\section{Discussion}

Extremolytes are defending substances that protect organisms from stress factors, such as heat, cold, high osmolarity, and dryness [27]. Each of the various members of the extremolyte family is preferably produced, absorbed, or accumulated from the environment under specific stress conditions [51]. The substances ectoine and hydroxyectoine, which are examined in more detail in this study, are mainly found under hypersaline conditions. Since they are substances compatible with the cellular metabolism that accumulate in the cytoplasm to balance external osmotic pressure, they are also called compatible solutes [52]. More and more studies are dedicated to the use of compatible solutes in the field of neurodegenerative diseases [53-56]. For example, in the context of Alzheimer research, ectoine and hydroxyectoine seem to be able to inhibit the aggregation of $\beta$-amyloid, which is responsible for plaque formation [56].

Although ectoine and hydroxyectoine are already part of current research in various areas, their effect on the retina and associated diseases was analyzed in this study for the first time. However, other osmotically active substances have been investigated for their potential therapeutic effect for retinal diseases. For example, a protective effect of betaine, which functions as a chaperone and protects against protein denaturation [57], has been demonstrated due to its inhibitory effect on the VEGF-mediated pathological neovascularization [58, 59].

Our first analyses of the osmolytes ectoine and hydroxyectoine showed a protective effect on the retina, evidenced by a significantly reduced loss of RGCs caused by hypoxia. Nevertheless, in comparison with control retinas, the loss of RGCs was not completely reversed. Interestingly, it has already been described in $\mathrm{HaCaT}$ cells that ectoine exerts its beneficial effects by activating the Akt-nuclear factor erythroid 2-related factor 2 (Nrf2) pathway, which in turn causes the expression of antioxidant proteins such as heme oxygenase 1 (HO-1) [60]. Moreover, it has been demonstrated before that the $\mathrm{Nrf} 2 / \mathrm{HO}-1$ system is one of the most important endogenous defense mechanisms against hypoxic stress [61] and also in the acute intraocular hypertension glaucoma model it was observed that a novel marine neuroprotectant agent can protect RGCs from acute ischemia/reperfusion injury by enhancing the Nrf2/HO-1 pathway [62]. Thus, it could also be possible that ectoine and hydroxyectoine protect the RGCs from $\mathrm{CoCl}_{2}$-induced hypoxia by activating the Akt/Nrf2 pathway.

Since macroglia plays an important role in many hypoxiainduced pathological mechanisms, the influence of ectoine or hydroxyectoine on this cell type was also investigated. Both substances had an influence neither on Müller cells nor on astrocytes. However, the sole administration of $\mathrm{CoCl}_{2} \mathrm{did}$ not increase the macroglia area compared with the control group. One reason for the lack of this observation could be the separation from the optic nerve and the vascular supply, since astrocytes migrate into the retina via blood vessels and the optic nerve head [63]. Moreover, the cultivation time and the process of cultivation could be used as a declaration for the lack of macrogliosis. Previous studies on the one hand showed that $\mathrm{CoCl}_{2}$-induced degeneration of the porcine retina revealed a macrogliosis after 4 days, which disappeared over time [47]. On the other hand, investigations on porcine retina demonstrated that the cultivation alone triggered a macroglia response whether additional degenerative substance induced a reduction of the macroglia signals in comparison with cultured controls $[26,46,64]$. This implies that the process of cultivation seems to have the strongest effect on the macroglia.

To further elucidate the cellular factors which were involved in the observed effects of ectoine and hydroxyectoine, we performed studies on apoptosis via caspase 3 and on hypoxia via HIF- $1 \alpha$, which acts as a major player in the $\mathrm{CoCl}_{2}$ induced hypoxia cascade. A reduction in the apoptosis rate was detectable after ectoine and hydroxyectoine application. Interestingly, ectoine was able to reduce the apoptosis rate in such amount that a significant difference to the control retinas was no longer detectable. In contrast, the addition of hydroxyectoine reduced the rate of apoptosis, but a significant difference compared with the control group was still observable. These observations are in line with previous studies on 
the Machado-Joseph disease, which investigated the protective effects of the compatible solutes ectoine, hydroxyectoine, and betaine on apoptotic cell death produced by the truncated Machado-Joseph disease gene. Again, only ectoine, but not hydroxyectoine or betaine, decreased apoptotic features [54]. Furthermore, $\mathrm{CoCl}_{2}$ provoked a significant increase in HIF$1 \alpha^{+}$cells. Interestingly, treatment with ectoine did not alter the number of hypoxic cells, neither in undamaged nor in $\mathrm{CoCl}_{2}-$ degenerated retinas. The fact that ectoine was unable to reduce the stabilization of HIF- $1 \alpha$, but significantly reduced the number of apoptotic RGCs, suggests that ectoine is affecting the final part of the hypoxia-related pathway. This assumption is supported by the fact that numerous studies have previously shown that ectoine has protective effects on heat, cold, and dryness by stabilizing proteins and cell membranes [65-68]. In contrast to ectoine, a significant decrease in HIF- $1 \alpha^{+}$RGCs was noted after the administration of hydroxyectoine. These observations indicate that the additional hydroxyl group of hydroxyectoine causes further interactions associated with the stabilization of HIF-1 $\alpha$, thereby affecting $\mathrm{CoCl}_{2}$-induced hypoxic retinal damage. Inter alia, a direct interaction between the additional hydroxy group and the hydrophilic head of the phospholipids is described, which disrupts processes at the cell membrane, such as the entrapment of vesicles [67]. Functional differences between ectoine and hydroxyectoine were not only detectable in our studies but also by other groups. In most cases, hydroxyectoine was superior to ectoine. For example, the application of hydroxyectoine caused a significant protein protection under heat stress in the enzyme lactate dehydrogenase model, while this effect was absent after ectoine treatment [69]. Moreover, E. coli K12 exhibited a higher survival rate after freeze-drying in the presence of hydroxyectoine than in the presence of ectoine [70]. Interestingly, examinations of the DNA melting temperature in the presence of ectoine or hydroxyectoine revealed that ectoine led to a lowering of the melting temperature, whereas hydroxyectoine increased it [71]. Since ectoine exerts a stronger influence on the apoptosis rate and hydroxyectoine on the number of hypoxic cells, the combination of both extremolytes might represent an approach that deserves further consideration. The combination of both extremolytes could increase the effects of the individual substances and thus the therapeutic effect. The positive effect of a combination therapy has already been demonstrated in the microbial growth of Streptomyces coelicolor A3(2). A mixture of $0.5 \mathrm{mM}$ ectoine and $0.5 \mathrm{mM}$ hydroxyectoine mediated a better osmoprotection than $1 \mathrm{mM}$ ectoine or $1 \mathrm{mM}$ hydroxyectoine alone [72]. Moreover, skin care products also use blends of ectoine and hydroxyectoine to combine the benefits of both extremolytes for the stability of phospholipid bilayer membranes [73].

In summary, in the present study, we were able to show for the first time that ectoine and hydroxyectoine are neuroprotective in a hypoxia-induced model of degenerative retinal ganglion cell damage. Thus, the application of both extremolytes appears to be an interesting new therapeutic approach for hypoxia-related eye diseases.

Acknowledgments The extremolytes ectoine and hydroxyectoine were provided by Bitop AG. We thank Gesa Stute for excellent technical support.

Funding Open access funding enabled and organized by Projekt DEAL.

\section{Compliance with ethical standards}

Conflict of interest The authors declare that they have no conflict of interest.

Ethical approval This article does not contain any studies with human participants or animals performed by any of the authors.

Open Access This article is licensed under a Creative Commons Attribution 4.0 International License, which permits use, sharing, adaptation, distribution and reproduction in any medium or format, as long as you give appropriate credit to the original author(s) and the source, provide a link to the Creative Commons licence, and indicate if changes were made. The images or other third party material in this article are included in the article's Creative Commons licence, unless indicated otherwise in a credit line to the material. If material is not included in the article's Creative Commons licence and your intended use is not permitted by statutory regulation or exceeds the permitted use, you will need to obtain permission directly from the copyright holder. To view a copy of this licence, visit http://creativecommons.org/licenses/by/4.0/.

\section{References}

1. Cohen LH, Noell WK (1965) Relationships between visual function and metabolism. In: Graymore $\mathrm{CN}$ (ed) Biochemistry of the Retina. Academic press Inc, Orlando, pp 36-50

2. Wangsa-Wirawan ND, Linsenmeier RA (2003) Retinal oxygen: fundamental and clinical aspects. Arch Ophthalmol 121(4):547557. https://doi.org/10.1001/archopht.121.4.547

3. Kaur C, Foulds WS, Ling EA (2008) Hypoxia-ischemia and retinal ganglion cell damage. Clin Ophthalmol 2(4):879-889. https://doi. org/10.2147/opth.s3361

4. Linsenmeier RA, Braun RD, McRipley MA, Padnick LB, Ahmed J, Hatchell DL, McLeod DS, Lutty GA (1998) Retinal hypoxia in long-term diabetic cats. Invest Ophthalmol Vis Sci 39(9):16471657

5. Harris A, Arend O, Danis RP, Evans D, Wolf S, Martin BJ (1996) Hyperoxia improves contrast sensitivity in early diabetic retinopathy. Br J Ophthalmol 80(3):209-213. https://doi.org/10.1136/bjo. 80.3.209

6. Flammer J (1994) The vascular concept of glaucoma. Surv Ophthalmol 38(Suppl):S3-S6. https://doi.org/10.1016/00396257(94)90041-8

7. Tielsch JM, Katz J, Sommer A, Quigley HA, Javitt JC (1995) Hypertension, perfusion pressure, and primary open-angle glaucoma. A population-based assessment. Arch Ophthalmol 113(2):216 221. https://doi.org/10.1001/archopht.1995.01100020100038 
8. Chung HS, Harris A, Evans DW, Kagemann L, Garzozi HJ, Martin B (1999) Vascular aspects in the pathophysiology of glaucomatous optic neuropathy. Surv Ophthalmol 43(Suppl 1):S43-S50. https:// doi.org/10.1016/s0039-6257(99)00050-8

9. EGS (2017) European Glaucoma society terminology and guidelines for Glaucoma, 4th edition - Chapter2: classification and terminology. Br J Ophthalmol 101(5):73-127. https://doi.org/10. 1136/bjophthalmol-2016-EGSguideline.002

10. Quigley HA, Broman AT (2006) The number of people with glaucoma worldwide in 2010 and 2020. Br J Ophthalmol 90(3):262267. https://doi.org/10.1136/bjo.2005.081224

11. Tham YC, Li X, Wong TY, Quigley HA, Aung T, Cheng CY (2014) Global prevalence of glaucoma and projections of glaucoma burden through 2040: a systematic review and meta-analysis. Ophthalmology 121(11):2081-2090. https://doi.org/10.1016/j. ophtha.2014.05.013

12. McDonnell F, Irnaten M, Clark AF, O'Brien CJ, Wallace DM (2016) Hypoxia-induced changes in DNA methylation Alter RASAL1 and TGFbeta1 expression in human trabecular meshwork cells. PLoS One 11(4):e0153354. https://doi.org/10.1371/journal. pone. 0153354

13. Tezel G, Wax MB (2004) Hypoxia-inducible factor 1alpha in the glaucomatous retina and optic nerve head. Arch Ophthalmol 122(9):1348-1356. https://doi.org/10.1001/archopht.122.9.1348

14. Semenza GL, Agani F, Iyer N, Jiang BH, Leung S, Wiener C, Yu A (1998) Hypoxia-inducible factor 1: from molecular biology to cardiopulmonary physiology. Chest $114(1 \mathrm{Suppl}): 40 \mathrm{~S}-45 \mathrm{~S}$. https:// doi.org/10.1378/chest.114.1_supplement.40s

15. Huang LE, Gu J, Schau M, Bunn HF (1998) Regulation of hypoxiainducible factor 1alpha is mediated by an O2-dependent degradation domain via the ubiquitin-proteasome pathway. Proc Natl Acad Sci U S A 95(14):7987-7992. https://doi.org/10.1073/pnas.95.14. 7987

16. Hellwig-Burgel T, Stiehl DP, Wagner AE, Metzen E, Jelkmann W (2005) Review: hypoxia-inducible factor-1 (HIF-1): a novel transcription factor in immune reactions. J Interferon Cytokine Res. 25(6):297-310. https://doi.org/10.1089/jir.2005.25.297

17. Lopez-Hernandez B, Cena V, Posadas I (2015) The endoplasmic reticulum stress and the HIF-1 signalling pathways are involved in the neuronal damage caused by chemical hypoxia. Br J Pharmacol 172(11):2838-2851. https://doi.org/10.1111/bph.13095

18. Ergorul C, Ray A, Huang W, Wang DY, Ben Y, Cantuti-Castelvetri I, Grosskreutz CL (2010) Hypoxia inducible factor-1alpha (HIF1alpha) and some HIF-1 target genes are elevated in experimental glaucoma. J Mol Neurosci : MN 42(2):183-191. https://doi.org/10. 1007/s12031-010-9343-Z

19. Reszec J, Zalewska R, Bernaczyk P, Chyczewski L (2012) HIF-1 expression in retinal ganglion cells and optic nerve axons in glaucoma. Folia Histochem Cytobiol 50(3):456-459. https://doi.org/10. $5603 / 19757$

20. Yamada K (2013) Cobalt: its role in health and disease. Met Ions Life Sci 13:295-320. https://doi.org/10.1007/978-94-007-7500-8 9

21. Caltana L, Merelli A, Lazarowski A, Brusco A (2009) Neuronal and glial alterations due to focal cortical hypoxia induced by direct cobalt chloride $(\mathrm{CoCl} 2)$ brain injection. Neurotox Res 15(4):348358. https://doi.org/10.1007/s12640-009-9038-9

22. Grasselli F, Basini G, Bussolati S, Bianco F (2005) Cobalt chloride, a hypoxia-mimicking agent, modulates redox status and functional parameters of cultured swine granulosa cells. Reprod Fertil Dev 17(7):715-720

23. Cheng Z, Yao W, Zheng J, Ding W, Wang Y, Zhang T, Zhu L, Zhou $F$ (2019) A derivative of betulinic acid protects human retinal pigment epithelial (RPE) cells from cobalt chloride-induced acute hypoxic stress. Exp Eye Res 180:92-101. https://doi.org/10.1016/j. exer.2018.12.011
24. Zimmerman MA, Biggers CD, Li PA (2018) Rapamycin treatment increases hippocampal cell viability in an mTOR-independent manner during exposure to hypoxia mimetic, cobalt chloride. BMC Neurosci 19(1):82. https://doi.org/10.1186/s12868-018-0482-4

25. del Olmo-Aguado S, Nunez-Alvarez C, Ji D, Manso AG, Osborne NN (2013) RTP801 immunoreactivity in retinal ganglion cells and its down-regulation in cultured cells protect them from light and cobalt chloride. Brain Res Bull 98:132-144. https://doi.org/10. 1016/j.brainresbull.2013.08.002

26. Kuehn S, Hurst J, Rensinghoff F, Tsai T, Grauthoff S, Satgunarajah Y, Dick HB, Schnichels S, Joachim SC (2017) Degenerative effects of cobalt-chloride treatment on neurons and microglia in a porcine retina organ culture model. Exp Eye Res 155:107-120. https://doi. org/10.1016/j.exer.2017.01.003

27. Rothschild LJ, Mancinelli RL (2001) Life in extreme environments. Nature 409(6823):1092-1101. https://doi.org/10.1038/35059215

28. Lippert K, Galinski EA (1992) Enzyme stabilization by ectoinetype compatible solutes; protection against heating, freezing and drying. Appl Microbiol Biotechnol 37:61. https://doi.org/10.1007/ BF00174204

29. Arakawa T, Timasheff SN (1985) The stabilization of proteins by osmolytes. Biophys J 47(3):411-414. https://doi.org/10.1016/ S0006-3495(85)83932-1

30. Malin G, Iakobashvili R, Lapidot A (1999) Effect of tetrahydropyrimidine derivatives on protein-nucleic acids interaction. Type II restriction endonucleases as a model system. J Biol Chem 274(11):6920-6929. https://doi.org/10.1074/jbc.274.11. 6920

31. Galinski EA, Pfeiffer HP, Truper HG (1985) 1,4,5,6-Tetrahydro-2methyl-4-pyrimidinecarboxylic acid. A novel cyclic amino acid from halophilic phototrophic bacteria of the genus Ectothiorhodospira. Eur J Biochem 149(1):135-139

32. Inbar L, Lapidot A (1988) The structure and biosynthesis of new tetrahydropyrimidine derivatives in actinomycin $\mathrm{D}$ producer Streptomyces parvulus. Use of 13C- and 15N-labeled L-glutamate and $13 \mathrm{C}$ and $15 \mathrm{~N}$ NMR spectroscopy. J Biol Chem 263(31): 16014-16022

33. Zaccai G, Bagyan I, Combet J, Cuello GJ, Deme B, Fichou Y, Gallat FX, Galvan Josa VM, von Gronau S, Haertlein M, Martel A, Moulin M, Neumann M, Weik M, Oesterhelt D (2016) Neutrons describe ectoine effects on water H-bonding and hydration around a soluble protein and a cell membrane. Sci Rep 6:31434. https://doi. org/10.1038/srep31434

34. Buenger J, Driller H (2004) Ectoin: an effective natural substance to prevent UVA-induced premature photoaging. Skin Pharmacol Physiol 17(5):232-237. https://doi.org/10.1159/000080216

35. Graf R, Anzali S, Buenger J, Pfluecker F, Driller H (2008) The multifunctional role of ectoine as a natural cell protectant. Clin Dermatol 26(4):326-333. https://doi.org/10.1016/j.clindermatol. 2008.01.002

36. Marini A, Reinelt K, Krutmann J, Bilstein A (2014) Ectoinecontaining cream in the treatment of mild to moderate atopic dermatitis: a randomised, comparator-controlled, intra-individual double-blind, multi-center trial. Skin Pharmacol Physiol 27(2):57-65. https://doi.org/10.1159/000351381

37. Werkhauser N, Bilstein A, Sonnemann U (2014) Treatment of allergic rhinitis with ectoine containing nasal spray and eye drops in comparison with azelastine containing nasal spray and eye drops or with cromoglycic acid containing nasal spray. J Allergy 2014: 176597. https://doi.org/10.1155/2014/176597

38. Sonnemann U, Moller M, Bilstein A (2014) Noninterventional open-label trial investigating the efficacy and safety of ectoine containing nasal spray in comparison with beclomethasone nasal spray in patients with allergic rhinitis. J Allergy 2014:297203. https://doi. org/10.1155/2014/297203 
39. Eichel A, Bilstein A, Werkhauser N, Mosges R (2014) Metaanalysis of the efficacy of ectoine nasal spray in patients with allergic rhinoconjunctivitis. J Allergy 2014:292545. https://doi.org/10. $1155 / 2014 / 292545$

40. Muller D, Lindemann T, Shah-Hosseini K, Scherner O, Knop M, Bilstein A, Mosges R (2016) Efficacy and tolerability of an ectoine mouth and throat spray compared with those of saline lozenges in the treatment of acute pharyngitis and/or laryngitis: a prospective, controlled, observational clinical trial. Eur Arch Oto-Rhino L 273(9):2591-2597. https://doi.org/10.1007/s00405-016-4060-Z

41. Sydlik U, Gallitz I, Albrecht C, Abel J, Krutmann J, Unfried K (2009) The compatible solute ectoine protects against nanoparticle-induced neutrophilic lung inflammation. Am J Respir Crit Care Med 180(1):29-35. https://doi.org/10.1164/rccm. 200812-19110C

42. Sydlik U, Peuschel H, Paunel-Gorgulu A, Keymel S, Kramer U, Weissenberg A, Kroker M, Seghrouchni S, Heiss C, Windolf J, Bilstein A, Kelm M, Krutmann J, Unfried K (2013) Recovery of neutrophil apoptosis by ectoine: a new strategy against lung inflammation. Eur Respir J 41(2):433-442. https://doi.org/10.1183/ 09031936.00132211

43. Unfried K, Kroker M, Autengruber A, Gotic M, Sydlik U (2014) The compatible solute ectoine reduces the exacerbating effect of environmental model particles on the immune response of the airways. J Allergy 2014:708458. https://doi.org/10.1155/2014/ 708458

44. Eichel A, Wittig J, Shah-Hosseini K, Mosges R (2013) A prospective, controlled study of SNS01 (ectoine nasal spray) compared to BNO-101 (phytotherapeutic dragees) in patients with acute rhinosinusitis. Curr Med Res Opin 29(7):739-746. https://doi.org/ 10.1185/03007995.2013.800474

45. Hurst J, Kuehn S, Jashari A, Tsai T, Bartz-Schmidt KU, Schnichels S, Joachim SC (2017) A novel porcine ex vivo retina culture model for oxidative stress induced by $\mathrm{H}(2) \mathrm{O}(2)$. Altern Lab Anim : ATLA 45(1):11-25

46. Kuehn S, Hurst J, Jashari A, Ahrens K, Tsai T, Wunderlich IM, Dick HB, Joachim SC, Schnichels S (2016) The novel induction of retinal ganglion cell apoptosis in porcine organ culture by NMDA an opportunity for the replacement of animals in experiments. Altern Lab Anim : ATLA 44(6):557-568

47. Maliha AM, Kuehn S, Hurst J, Herms F, Fehr M, Bartz-Schmidt KU, Dick HB, Joachim SC, Schnichels S (2019) Diminished apoptosis in hypoxic porcine retina explant cultures through hypothermia. Sci Rep 9(1):4898. https://doi.org/10.1038/s41598-01941113-4

48. Horstmann L, Schmid H, Heinen AP, Kurschus FC, Dick HB, Joachim SC (2013) Inflammatory demyelination induces glia alterations and ganglion cell loss in the retina of an experimental autoimmune encephalomyelitis model. J Neuroinflammation 10:120. https://doi.org/10.1186/1742-2094-10-120

49. Reinehr S, Kuehn S, Casola C, Koch D, Stute G, Grotegut P, Dick HB, Joachim SC (2018) HSP27 immunization reinforces AII amacrine cell and synapse damage induced by S100 in an autoimmune glaucoma model. Cell Tissue Res 371(2):237-249. https:// doi.org/10.1007/s00441-017-2710-0

50. Casola C, Reinehr S, Kuehn S, Stute G, Spiess BM, Dick HB, Joachim SC (2016) Specific inner retinal layer cell damage in an autoimmune Glaucoma model is induced by GDNF with or without HSP27. Invest Ophthalmol Vis Sci 57(8):3626-3639. https://doi. org/10.1167/iovs.15-18999R2

51. Oren A (1999) Bioenergetic aspects of halophilism. Microbiol Mol Biol Rev : MMBR 63(2):334-348
52. Antón J (2011) Compatible Solute. In: Gargaud M, Amils R, Quintanilla JC et al (eds) Encyclopedia of astrobiology. Springer, Berlin Heidelberg, pp 351-352. https://doi.org/10.1007/978-3-64211274-4 336

53. Arora A, Ha C, Park CB (2004) Inhibition of insulin amyloid formation by small stress molecules. FEBS Lett 564(1-2):121-125. https://doi.org/10.1016/S0014-5793(04)00326-6

54. Furusho K, Yoshizawa T, Shoji S (2005) Ectoine alters subcellular localization of inclusions and reduces apoptotic cell death induced by the truncated Machado-Joseph disease gene product with an expanded polyglutamine stretch. Neurobiol Dis 20(1):170-178. https://doi.org/10.1016/j.nbd.2005.02.011

55. Kanapathipillai M, Ku SH, Girigoswami K, Park CB (2008) Small stress molecules inhibit aggregation and neurotoxicity of prion peptide 106-126. Biochem Biophys Res Commun 365(4):808-813. https://doi.org/10.1016/j.bbrc.2007.11.074

56. Kanapathipillai M, Lentzen G, Sierks M, Park CB (2005) Ectoine and hydroxyectoine inhibit aggregation and neurotoxicity of Alzheimer's beta-amyloid. FEBS Lett 579(21):4775-4780. https:// doi.org/10.1016/j.febslet.2005.07.057

57. Caldas T, Demont-Caulet N, Ghazi A, Richarme G (1999) Thermoprotection by glycine betaine and choline. Microbiology 145(Pt 9):2543-2548. https://doi.org/10.1099/00221287-145-92543

58. Kim YG, Lim HH, Lee SH, Shin MS, Kim CJ, Yang HJ (2015) Betaine inhibits vascularization via suppression of Akt in the retinas of streptozotocin-induced hyperglycemic rats. Mol Med Rep 12(2): 1639-1644. https://doi.org/10.3892/mmr.2015.3613

59. Park SW, Jun HO, Kwon E, Yun JW, Kim JH, Park YJ, Kang BC, Kim JH (2017) Antiangiogenic effect of betaine on pathologic retinal neovascularization via suppression of reactive oxygen species mediated vascular endothelial growth factor signaling. Vasc Pharmacol 90:19-26. https://doi.org/10.1016/j.vph.2016.07.007

60. Hseu YC, Chen XZ, Vudhya Gowrisankar Y, Yen HR, Chuang JY, Yang HL (2020) The skin-whitening effects of Ectoine via the suppression of alpha-MSH-stimulated Melanogenesis and the activation of antioxidant Nrf2 pathways in UVA-irradiated keratinocytes. Antioxidants (Basel) 9(1). https://doi.org/10.3390/ antiox 9010063

61. Kolamunne RT, Dias IH, Vernallis AB, Grant MM, Griffiths HR (2013) Nrf2 activation supports cell survival during hypoxia and hypoxia/reoxygenation in cardiomyoblasts; the roles of reactive oxygen and nitrogen species. Redox Biol 1:418-426. https://doi. org/10.1016/j.redox.2013.08.002

62. Sheng L, Lu B, Chen H, Du Y, Chen C, Cai W, Yang Y, Tian X, Huang Z, Chi W, Lin S, Yan G, Yin W (2019) Marine-steroid derivative 5alpha-Androst-3beta, 5alpha, 6beta-triol protects retinal ganglion cells from ischemia(-)reperfusion injury by activating Nrf2 pathway. Mar Drugs 17(5). https://doi.org/10.3390/ md17050267

63. Nakazawa T, Tachi S, Aikawa E, Ihnuma M (1993) Formation of the myelinated nerve fiber layer in the chicken retina. Glia 8(2): 114-121. https://doi.org/10.1002/glia.440080207

64. Taylor L, Arner K, Ghosh F (2016) N-methyl-N-nitrosoureainduced neuronal cell death in a large animal model of retinal degeneration in vitro. Exp Eye Res 148:55-64. https://doi.org/10. 1016/j.exer.2016.05.023

65. Knapp S, Ladenstein R, Galinski EA (1999) Extrinsic protein stabilization by the naturally occurring osmolytes beta-hydroxyectoine and betaine. Extremophiles 3(3):191-198

66. Zhang L, Wang Y, Zhang C, Wang Y, Zhu D, Wang C, Nagata S (2006) Supplementation effect of ectoine on thermostability of 
phytase. J Biosci Bioeng 102(6):560-563. https://doi.org/10.1263/ jbb. 102.560

67. Harishchandra RK, Wulff S, Lentzen G, Neuhaus T, Galla HJ (2010) The effect of compatible solute ectoines on the structural organization of lipid monolayer and bilayer membranes. Biophys Chem 150(1-3):37-46. https://doi.org/10.1016/j.bpc.2010.02.007

68. Smiatek J, Harishchandra RK, Rubner O, Galla HJ, Heuer A (2012) Properties of compatible solutes in aqueous solution. Biophys Chem 160(1):62-68. https://doi.org/10.1016/j.bpc.2011.09.007

69. Borges N, Ramos A, Raven ND, Sharp RJ, Santos H (2002) Comparative study of the thermostabilizing properties of mannosylglycerate and other compatible solutes on model enzymes. Extremophiles 6(3):209-216. https://doi.org/10.1007/ s007920100236

70. Louis P, Trtiper HG, Galinski EA (1994) Survival of Escherichia coli during drying and storage in the presence of compatible solutes. Appl Microbiol Biotechnol 41:684-688

71. Schnoor M, Voss P, Cullen P, Boking T, Galla HJ, Galinski EA, Lorkowski S (2004) Characterization of the synthetic compatible solute homoectoine as a potent PCR enhancer. Biochem Biophys Res Commun 322(3):867-872. https://doi.org/10.1016/j.bbrc. 2004.07.200

72. Bursy J, Kuhlmann AU, Pittelkow M, Hartmann H, Jebbar M, Pierik AJ, Bremer E (2008) Synthesis and uptake of the compatible solutes ectoine and 5-hydroxyectoine by Streptomyces coelicolor A3(2) in response to salt and heat stresses. Appl Environ Microbiol 74(23):7286-7296. https://doi.org/10.1128/AEM.00768-08

73. Herzog M, Dwivedi M, Kumar Harishchandra R, Bilstein A, Galla HJ, Winter R (2019) Effect of ectoine, hydroxyectoine and betahydroxybutyrate on the temperature and pressure stability of phospholipid bilayer membranes of different complexity. Colloids Surf B: Biointerfaces 178:404-411. https://doi.org/10.1016/j.colsurfb. 2019.03.026

Publisher's note Springer Nature remains neutral with regard to jurisdictional claims in published maps and institutional affiliations. 